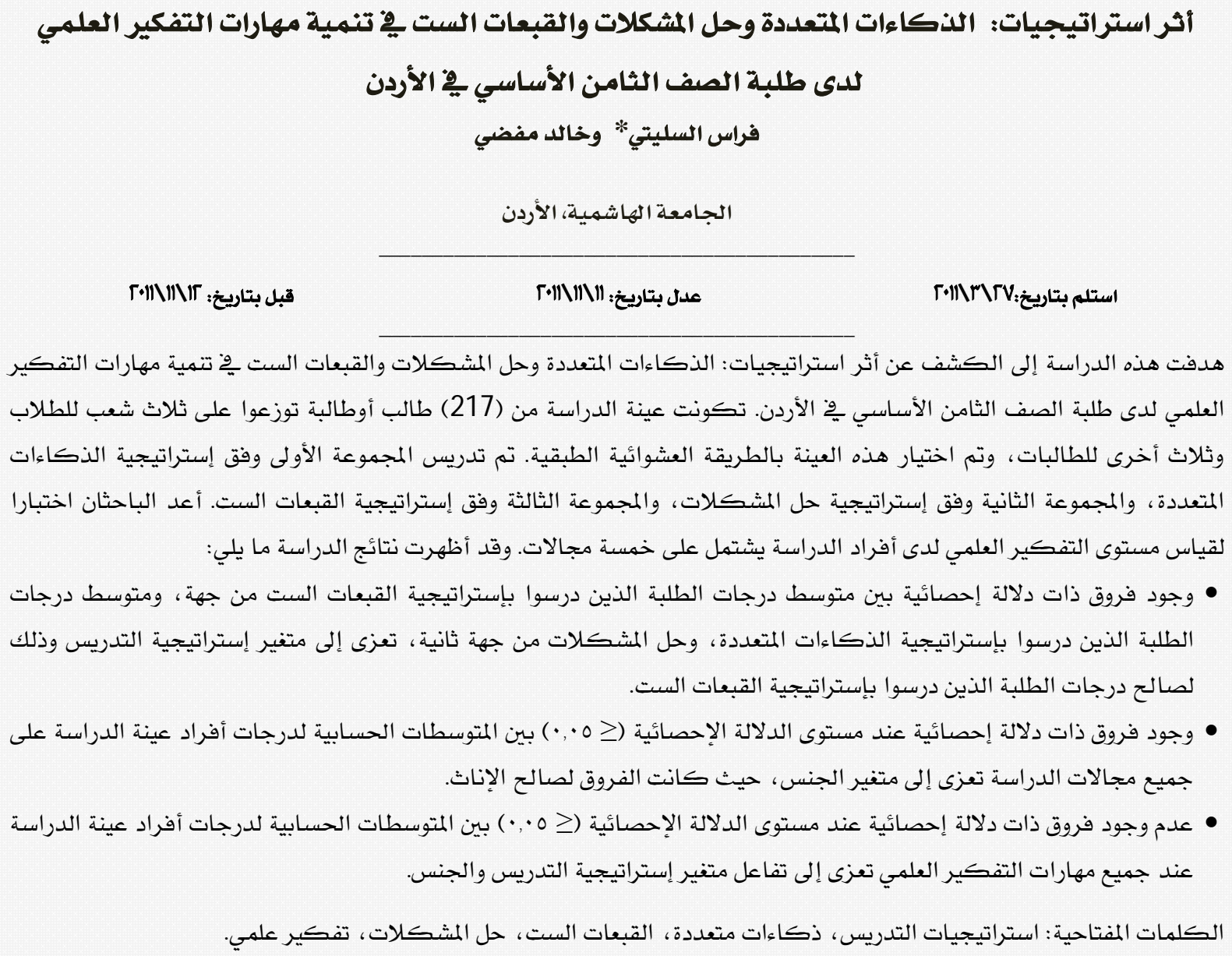

\title{
The Effect of the Strategies of Multiple-Intelligences and Six Hats Strategies and Problem Solving in the D evelopment of Eighth G rader's Scientific Thinking Skills in Jordan.
}

Feras A I Sulaiti* \& khaled Mifdy

Hashemite University, Jordan

This study aimed to reveal the impact of the strategies of multiple intelligences, problem solving, and the six hats on the development of scientific thinking skills among students in eighth grade in Jordan. The study took place in the first semester 2010-2011. The sample consisted of (217) students who were divided into three groups for boys and three for girls. The sample was a stratified random sample. The first group was taught according to the strategy of multiple intelligence, and the second group according to the strategy of problem-solving, while the third was taught according to the strategy of the six hats. Researchers prepared a test to measure the level of scientific thinking among members of the study. The instrument included five areas. The results of the study were:

- There were statistically significant differences between the average score of students who studied according to the six hats and the average score of students who studied according to the multiple intelligence, and problem solving in favor of the former group.

- Females outscored males ( $p \leq .05)$

- There was no significant interaction effect between teaching strategy and gender at $(p \leq 0.05)$.

Keywords: Teaching Strategies, Multiple Intelligences, Six Hats, Problem Solving, Scientific Thinking. *ferasalslaiti@yahoo.com 


\section{خلفية الدراسة}

(Wilson, ) التفكير العلمي بمنهجيته العلمية وطرق تتفيذها

وللتفكير العلمي أهمية كبيرة في مجال تدريس العلوم بشكل خاص، إذ إن طبيعة العلوم تتضمن مجموعة واسعة

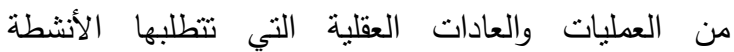
والاستقصاءات العلمية كعليات العلم الأساسية (الملاحظة، والتصنيف، والقياس، واستخدام الأرقام، والتتبؤ والاستدلال)

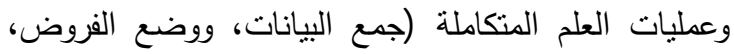

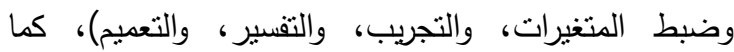
يتضمن تدريس العلوم إجراء الاستقصاءات العلمية المنظمة، وحل المشكلات (Keith et al., 2004). ولذلك يعد تدريس العلوم مجالا خصبا لتتمية التفكير العلمي لما تتميز به طبيعة

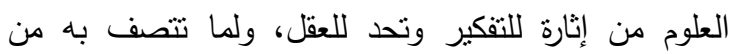

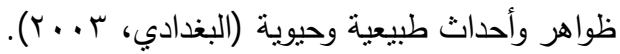
وبما أن تعلم العلوم من أجل الفهم وتتمية مهارات التفكير العلمي، واكتساب المفاهيم العلمية من النتاجات الراقية التي

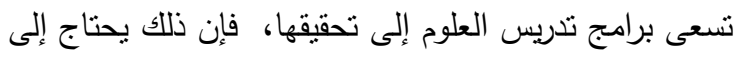
طرائق واستراتيجيات تدريس متتوعة يمكن من خلالها تحقيق هذه النتاجات، وعلى وجه الخصوص ما يتعلق منها باكتساب الطلبة التفكير ومهاراته، مما يزودهم بالقدرة على مواجهة

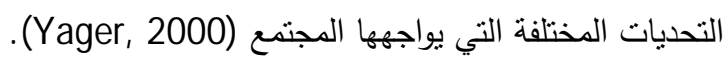
وعلى الرغم من أن تدريس العلوم بستلزم من الطلبة

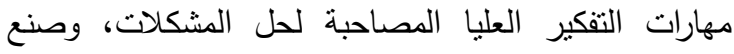
القرارات وكما يشير إلى ذلك هيرد (Hurd, 1994)، فإن

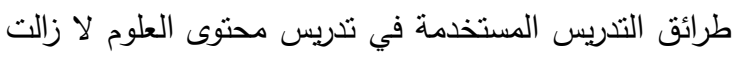

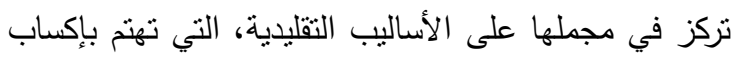
الطلبة المعارف والدفاهيم لذاتها وليس لقيمتها بالنسبة إليهم؛ مما يجعل دور الطالب سلبيا في تعلمه (Brown, 1995). كما أن مناهج العلوم لا زالت تركز في الغالب على زيلى لعيادة

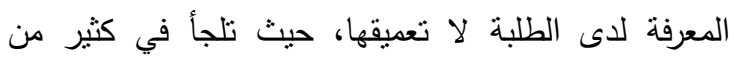

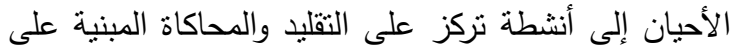

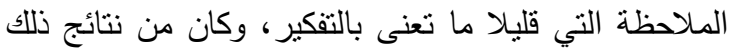

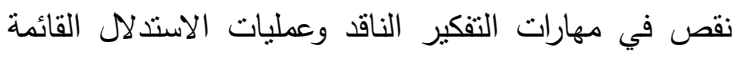
على المنطق والبرهان لدى الطلبة، كما ساهم في بناء
يشهر تدريس العلوم تطور او اسعاو اهتماما متزايدا في البلدان المتقدمة والنامية على حد سواء, ويرافق هذا الاهتمام مهالات عديدة ترمي إلى نظوير طرائق تدريس العلوم

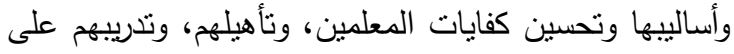
طرائق بديلة تساعد في تحقيق الأهداف المرجوة من تعلم

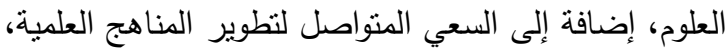
التي تركز على الفهم والتفكير وحل المشكلات.

ويرجع الاهتمام المتزايد بالتربية العلمية إلى النمو المنسارع في العلوم وتزايد توظيفها، و الى تتوع مصادر

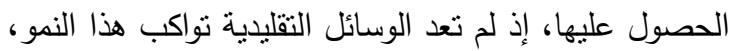
وتسهم في التتمية بفاعلية ؛ مما أدى إلى زيادة الحاجة إلى لى لى لئل مبادرات خلاقة، تهيئ للفرد فرصا مفتوحة لتعلم العلوم بحيث تلائم حاجاته الحاضرة والمستقبلية، وتمكنه من المساهمة

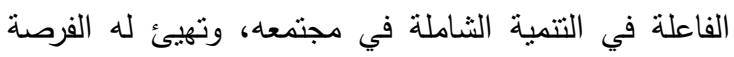
لحل مشكلاته اليومية National Research Council).

NRC, 1996)

يثير ديفسون وويرشام (Davidson and 1992) أنه وبحلول عام . W. Worsham,

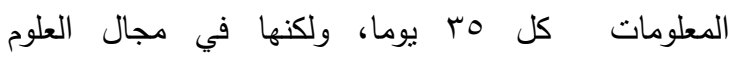
والتكنولوجيا قد تتضاعف مرتين كل •r شهرا. ومن هنا أصبح الهحف الرئيس من التربية العلمية الحديثة تتمية

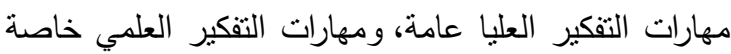

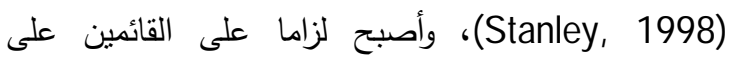
العملية التعليمية الاهتمام بتعليم الطلبة مهارات التفكير النقدي Cotton, والإبداعي والمنطقي والعلمي وتتميتها لديهم

التقكير هو الطريق الصحيح نحو الإبداع في شتى

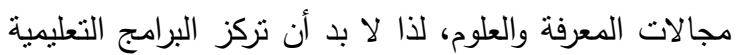

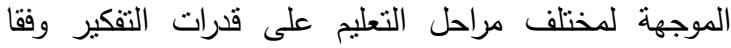
لكسار الكنهجية العلمية، كما أنه لا بد من تغيير النظرة

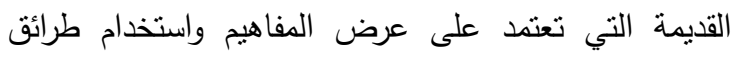
التدريس التقليدية إلى النظرة الحديثة التي تكفل للطالب تتمية

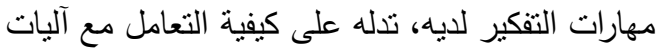


والموجودة عند الفرد، وأن كل شخص يمنلك عددا من أنواع الذكاء وليس ذكاء واحدا، وأن الأفراد يتعلمون ما هو مناسب لأنواع الذكاءات التي يمتلكونها ـ وبالتالي فإن نظرية الذكاء

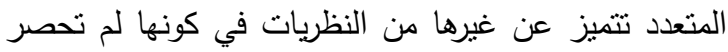

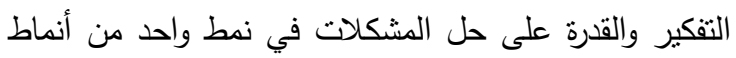
الذكاء, بل اعتبرت أن كل نمط من أنماط الذكاء المتعدد هو قدرة معرفية تتضمن في حد ذاتها استراتيجيات محددة لحل المشكلات (Armstrong, 1994) .

إن لافتراضات نظرية الذكاء المتعدد تطبيقات واسعة

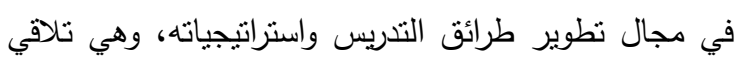
إقبالا كبيرا من المربين والطلبة لما لها من انعكاسات واضحة على العملية التدريسية بمجملها، فهي تلبي حاجات المعلمين

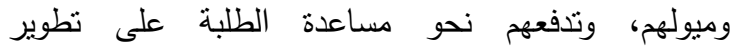
استراتيجيات متتوعة للتفكير وحل الشكلات، كما أن هذه النظرية تفتح آفاقاو اسعة أمام الددرسين لتتويع استراتيجيات تدريسهم داخل غرفة الصف بما يتوافق مع الأنماط التعلمية

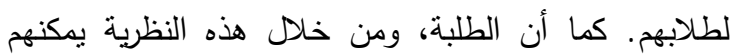

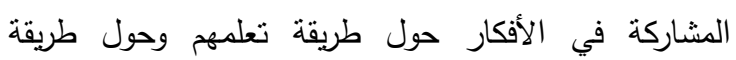
تفكيرهم، ثم إنهم يسنطيعون الششاركة في أنشطة التعلم

الفردية والجماعية (Gardner, 1983 Armstrong, 1994). برزت فكرة القبعات الست في التفكبر من أن هناك اتجاهات مختلفة للتفكير تدعو المفكرين للنظر إليها، وأن اتجاه التفكير يمكن أن يتغير، وترمز ألوان قبعات التفكير إلى لإن التيل اتجاهات التفكير المختلفة التي تظهر علاقة بين قبعة التفكير

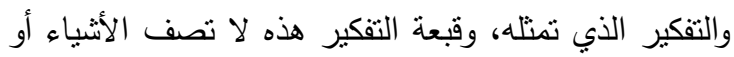

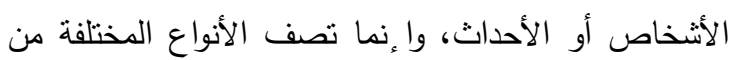
السلوك التي يمارسها الدفكر (DeBono, 1999). ورد في الأدب التزبوي العديد من الآراء المتعلقة بالقبعات الست حيث بشير دي بونو (DeBono, 1992) إلى أن القبعات الست أداة فعالة في تغيير طريقة تفكير بلتير

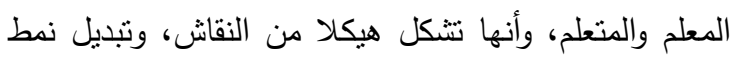
التفكير الواحد إلى ستة أنماط للتفكير فتوفر علاجا إبداعيا

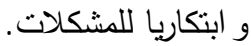

أما جروس (Gross, 1998) فيرى أن القبعات الست

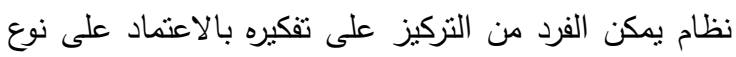
واحد من التفكير في كل وقت، كما يمكنه من نقل تفكيره من
تصورات خاطئة عن ماهية العلوم وطبيعتها لديهم (كييف

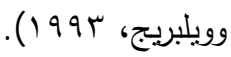

وتبرز أهمية استراتيجيات التدريس من خلا الدور الذي

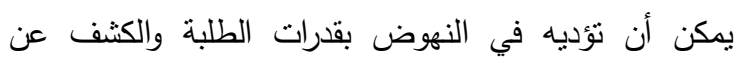
إمكانياتهم، وتتمية قدرات التفكير لديهم، وتطوير استعدادهم

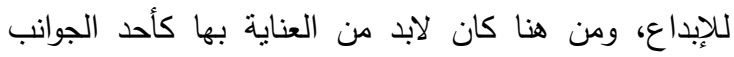
الرئيسة في عملية التعلم. كما أن استخدام استراتيجيات تعلم وتعليم متتوعة ومتميزة ومعتمدة على التفكير تسهم في إثراء معلومات الطلبة وتتمية مهاراتهم العقلية الدختلفة، وتدربهم

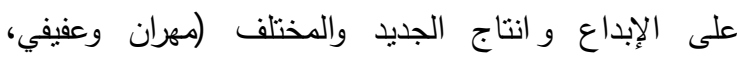
. (1991

يشير الأدب التنربوي إلى أنه يمكن اعتبار استراتيجيات

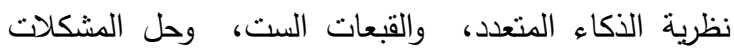
التي تنتاولها هذه الدراسة من الاستراتيجيات التي تهنم بالتفكير ومهاراته، وترفع من مستواه لدى الطلبة، كما أثنارت

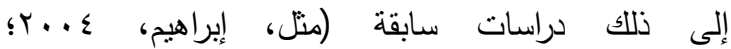

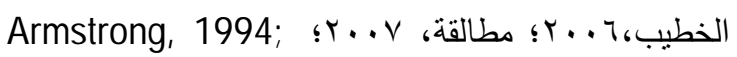
Batchelor, 2000;

DeBono,1992;

.Gardner,1983)

ترتكز نظرية الذكاء المتعدد على مجموعة من المبادئ أبرزها: أن الفرد يمنلك أنواعا من الذكاء تضم: النئ (الذكاء

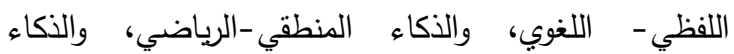
البصري -المكاني، والذكاء الموسيقي -الإيقاعي, والذكاء الزياء الجسمي -الحركي، والذكاء الثخصي -الخارجي، والذكاء الأاءياء الثخصي -الداخلي، والذكاء الطبيعي - البيئي)، ويرى جاردنر النياه

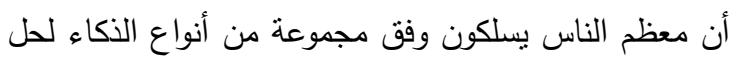

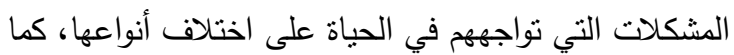
أن الذكاء لاى معظم الناس يظهر كيفية تآزر كل الذكاءات الأخرى ؛ لنتكل نتاجا هو نوليفة لعدد من الذكاءات، ومن لتأن

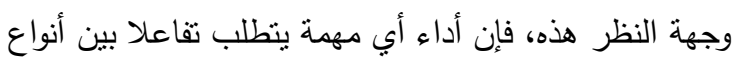
الذكاء المتعدد التي يمتلكها الفرد (Gardner, 1983). ويورد عبيدات وأبو السميد (Y... (Y) بعض المسلمات التي تقوم عليها نظرية الذكاءات المتعددة ومنها: أنه ليس

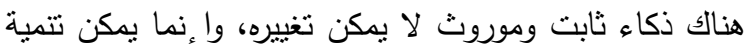

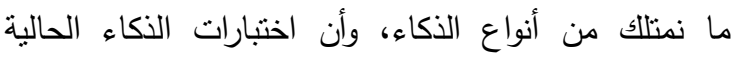
اختبارات لغوية ومنطقية فقط، ولا تغطي أنواع الذكاء المختلفة 
من أساليب التنريس التي نؤكد تتمية التفكير العلمي والاستقصاء هو التدريس باستخدام حل المشكلات؛ حيث يتم فيه وضع الطلبة في مشكلة قابلة للبحث و التجريب والاستقصاء، وتتحدى تفكيرهم وتحفزهم على التعلم، وهذا الأسلوب يكسب الطلبة تعلما ذا معنى وشعورا حقيقيا

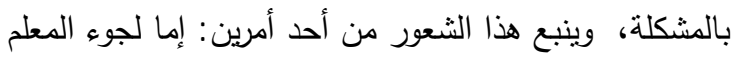

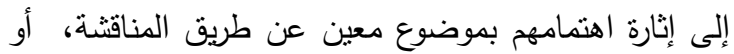
تتبع المشكلة تلقائيا في أثناء الدراسة المعتادة، فإذا ما ظهرت

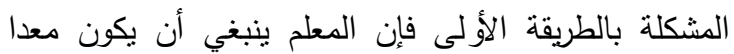
نفسه لتقديم العروض العلمية اللازمة، أما في الحالة الثانية

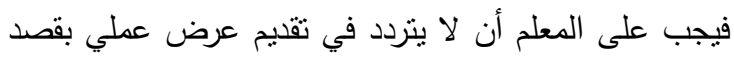
الوصول إلى إجابات لما أثثير من أسئلة إذا كان ذللك ممكنا في الوقت الدخصص لللدر (الدمرداش، 9Av ( )). ويثير أندرسن (Anderson, 1995) إلى أن موقف

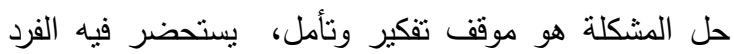
خبراته السابقة، ويجري فيه الكثير من العمليات المعرفية

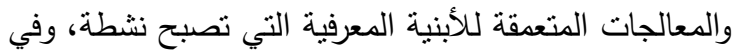

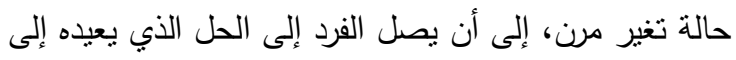

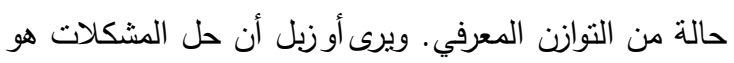
بحد ذاته عملية تعلم استكثافي ذي معنى؛ أي أن للمتعلم دورا إيجابيا في تحقيقها، فهو لا يتلقى الحل من غيره، واءنما ديا يبذل جها فكريا لإنجازه ثم يقوم بدمجها في بنائه المعرفي

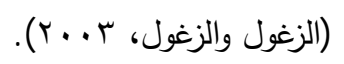

\section{مشكلة الدر اسة و أسئلتها:}

يعد اكتساب الطلبة للففاهيم العلمية وتتمية تفكيرهم

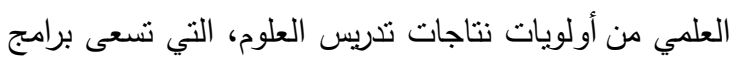

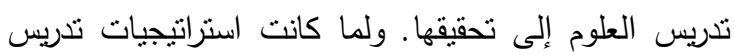
العلوم تؤدي دورا رئيسا في تحقيق هذه النتاجات, فإن البحث قائم على استراتيجيات تفكير يمكن توظيفها داخل غرفة لإنة الصف لتحقيق هذه الأهداف في تدريس العلوم. وتعد

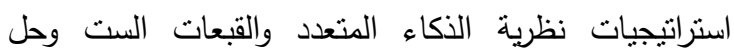
المشكلات من الاستراتيجيات التي من الممكن أن يكون لهاهيات

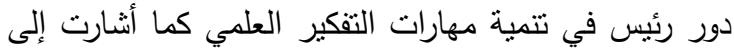

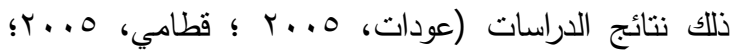

نمط لآخر ، وللتركيز على نمط تفكير واحد من قبل المتعلم المفكر يجب عليه لبس قبعة واحدة فقط من هذه القبعات. أما باتتلر (Batchelor, 2000) فيرى أن أسلوب التفكير بالقبعات الست بمكن توظيفه في مواقف تدريسية

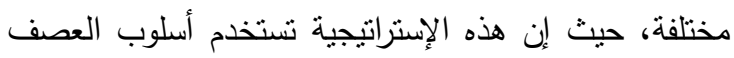
الفكري, وحل المشكلات، والتفكير الجانبي والتفكير البناء، وهذه المراحل ضرورية في أثناء التنريس، كما أن الألوان تساعد الطلبة على ست طرق منفصلة للتفكير ، مما يسهم في تعليم الطلبة عملية التأمل والمراجعة، ومعرفة أن اختلاف التفكير أمر ضروري في المواقف التعليمية المختلفة.

تعود إستراتيجية حل المشكلات إلى الحركة التقدمية،

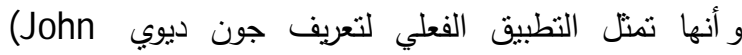
للتفكير التأملي، والحقيقة أن التعليم وفق هذه الإنتراتيجية وضع أصلا لتدريب الأطباء على كيفية معالجة المشكلات الطبية وحلها، ومن ثم تبنت هذه الإستراتيجية عدد من المدارس بثكل متزايد، بدءا من رياض الأطفال وحتى المراحل الثانوية، وفي المواد الدراسية جميعها، حيث

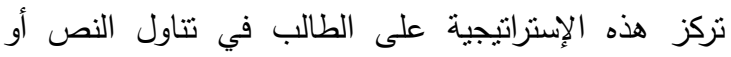
المادة، مستخدما مهارات التفكير التأملي والنقدي، ومهارات

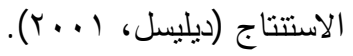

لقد شاع استخدام "حل الشكلات" في نتاول القضايا العلمية حتى ذهب بعض الباحثين إلى اعتبارها طريقة يتم بها

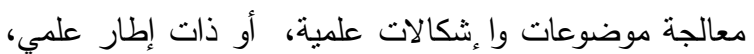
غير أن هناك العديد من الباحثين في مجالات الدراسات الاجتماعية والعلوم الإنسانية أفادوا بأهمية هذه الطريقة في تدريس المواد الدراسية المختلفة، حيث أجريت دراسات عليدة الإنية

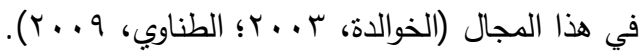
تقوم إستراتيجية حل المشكلات على خمس خطوات مترابطة ومتسلسلة تشمل: شعور القارىء بالمشكلة وتحليدها عبر نص القراءة مدار البحث، ثم وضع الفروض المناسبة

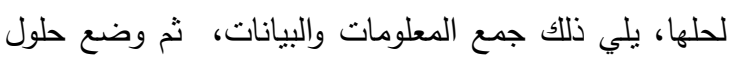
مناسبة من خلال التحقق من صحة الفروض المرتبطة بالمشكلة في النص الدقروء (سعادة، 919 1). 
الاراسة بحوثا أخرى في مجال متغيراتها المستقلة والتابعة في إطار مكاني وتعليمي أوسع.

\section{حدود الدر اسة ومحدداتها:}

تتقيد درجة تعميم نتائج هذه الدراسة بعدد من المحددات

1. يتحدد مجتمع الدراسة بطلبة الصف الثامن

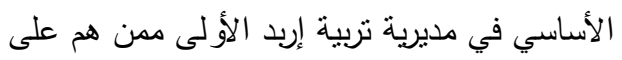

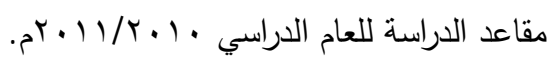

r. يتحدد موضوع تدريس العلوم بمفاهيم علمية من

$$
\text { منهاج الصف الثامن الأساسي. }
$$

\section{مصطلحات الدر اسة و تعريفاتها:}

الإستراتيجية التدريسية: وتعني الخطوات التي

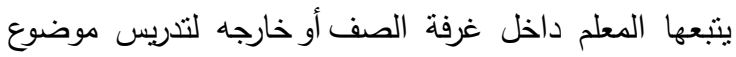
معين بغية تحقيق أهداف تربوية محددة ومخطط لها مسبقا، بحيث تتمل مجموعة الخطوات والإجراءات المتتابعة والمتتاسقة التي يقوم بها المعلم والطالب في أثناء ندريس ذلك

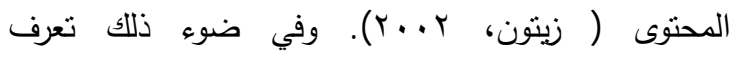

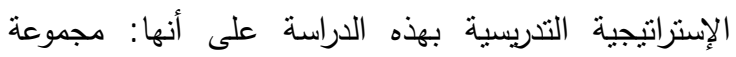

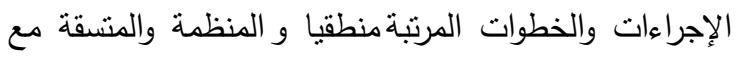

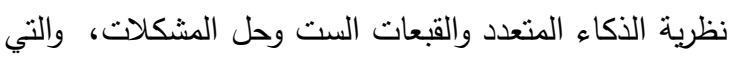
تثتنمل على طرق التدريس ووسائله وأساليبه وأنشطته ومداخله

$$
\text { وأساليب التقويم التي استخدمت في هذه الدراسة. }
$$

التفكير العلمي: يعرف التفكير العلمي على أنه استقصاء

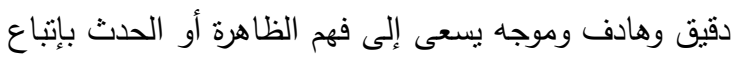

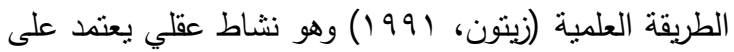
البرهان بالتجربة والدليل بستخدمه الفرد في حل المشكلات التي نواجهه بمنهجية علمية منظمه، ويقوم على عمليات العلم

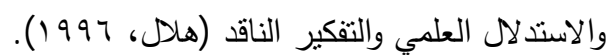
وفي ضوء ذلك فقد تم تحديد دلالاته في هذه الدراسة

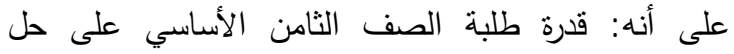

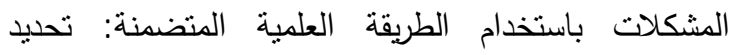

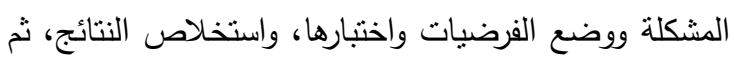
تعميمها، وتم قياسه بالدرجة لأداء الطالب على اختبار

$$
\text { التفكير العلمي الذي أعد في هذه الدراسة. }
$$

Serdar, 2005; Goodnough, 2000; Novak, .(2002; Williamson \& Perrow, 2003

يثير واقع تدريس العلوم في الأردن إلى تدني مستوى تحصيل الطلبة في المواد العلمية وتدني اكتسابهم للمفاهيم

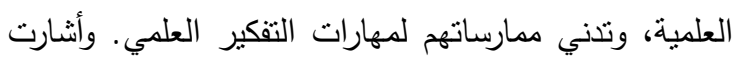

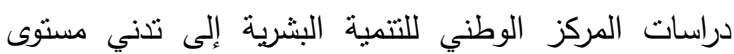
طلبة الأردن على اختبارات العلوم والرياضيات الدولية مقارنة

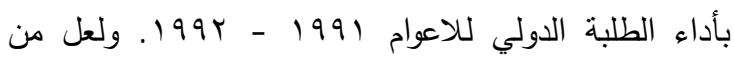

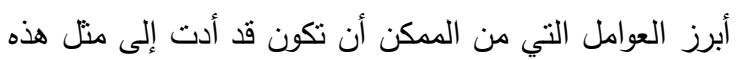

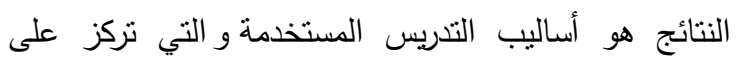
الحفظ والتلقين والاستظهار، وتغفل قدرات الطلبة التفكيرية

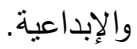

وعليه فإن مشكلة هذه الدراسة تمثلت بالسؤال الرئيس

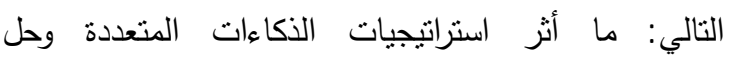
المشكلات والقبعات الست في تتمية مهارات التفكير العلمي لاى طلبة الصف الثامن الأساسي في الأردن؟ فئه

وقد انبثق عن هذا السؤال، الأسئلة الفرعية التالية؟ ا. هل توجد فروق ذات دلالة إحصائية بين متوسطات درجات الطلبة في مهارات التفكير العلمي تعزى إلى الى

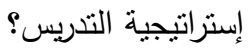
r. هل توجد فروق ذات دلالة إحصائية بين متوسطات درجات الطلبة في مهارات التفكير العلمي تعزى إلى دلى

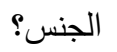
r. هل نوجد فروق ذات دلالة إحصائية بين متوسطات

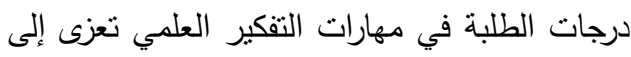
التفاعل بين إستراتيجية التدريس والجنس؟

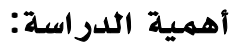

تكتسب هذه الدراسة أهمية في كونها تحدد

إجراءات عملية لاستخدام استراتيجيات تدريس قائمة على لانى تتمية التفكير في أثناء عملية التعلم, وهذه الاستراتيجيات هي: إستراتيجية الذكاء المتعدد، ولوستراتيجية القبعات الست، و استراتيجية حل المشكلات، وذللك عن طريق تدريس طلبة لئن الصف الثامن الأساسي محتوى العلوم. كما أنها تقدم دليلا تجرييا لأثر تدريس العلوم وفقا لتلك الإستراتيجيات في تتمية مهارات التفكير العلمي لدى الطلبة, وقد يثير موضوع هذه 
أثر استراتيجيات: الذكاءات المتعددة وحل المشكلات والقبعات الست فِّ تنمية مهارات التفكير العلهي لدى طلبة الصف الثامن الأساسي ِِّ الأردن

فراس السليتي وخالد مفضي

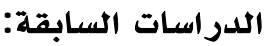

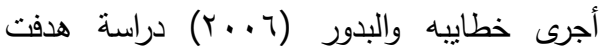
الكثف عن أثز استخدام استراتيجيات الذكاءات المتعددة، في اكتساب طلبة الصف السابع الأساسي في الأردن لمهارات عمليات العلم. تكونت عينة الدراسة من (90) طالبا وطالبة

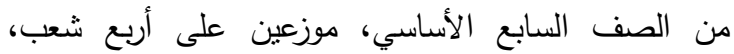

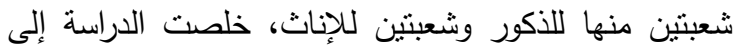
تفوق المجموعات التي درست باستخدام استراتيجيات الذكاءات المتعددة على المجموعات التي درست وفق الطريقة التقليدية، كما أظهرت تفوق الإناث على الذكور في اكتساب

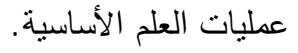

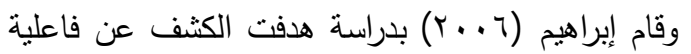

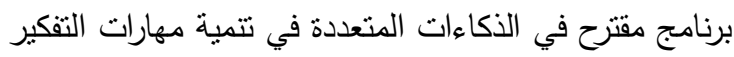
الإبداعي لدى معلمي العلوم، كما هدفت الكثف عن فاعلية البرنامج في تتمية مهارات حل المشكلات لدى طلبة المرحلة

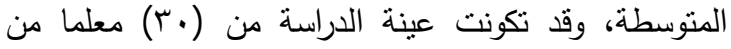

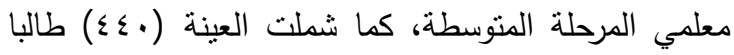

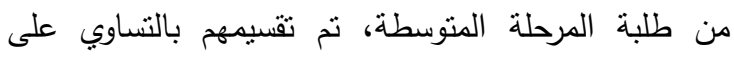
المجموعات التجريبية والضابطة، واستخدم الباحث مقياس التدريس الإبداعي لمعلمي العلوم، ومقياس الذكاءات المتعددة

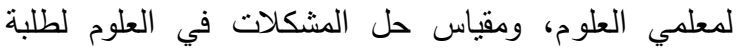

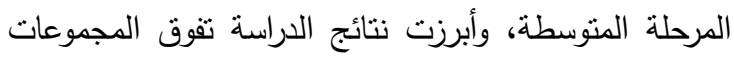
التجريبية على الضابطة في مهارة حل المشكلات في العلوم

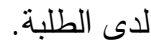

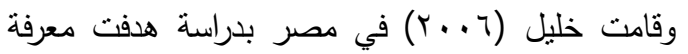

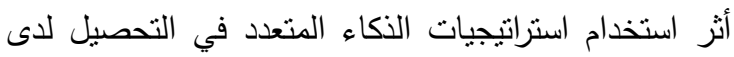
طلبة الصف الرابع الابتدائي، وفي تتمية مهارات عمليات العلم والتفكير التوليدي لديهم . تكونت عينة الدراسة من (ــ) طالبا، استخدت الباحثة اختبارا تحصيليا، واختبارا لمهارات

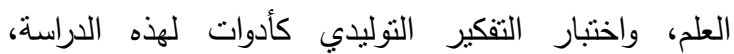
وأظهرت الدراسة وجود فروق ذات دلالة إحصائية لصالح المجموعة التجرييية في الاختبار التحصيلي، واختبار مهارات العلم.و أجرى سيردار (Serdar, 2005) في تركيا دراسة فئة هدفت معرفة أنز التدريس القائم على نظرية الذكاءات المتعددة في الأداء التنريسي والتحصيل العلمي لاى طلبة

\section{استراتيجيات نظرية الذكاءات المتعددة:}

وهي استراتيجيات نقوم على أساس أن الفرد يمنلك

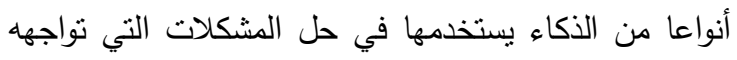
بحيث تتفاعل هذه الذكاءات عند أداء مهمة معينة (Gardner, 1983). وفي ضوء ذلك حددت هذه الاستراتيجيات في هذه الدراسة بأنها: استراتيجيه التنريس التي تتضمن مجموعة الخطوات والإجراءات المنظمة والمرتبة والمخطط لها التي يستخدمها المعلم من حيث تتفيذ الأنشطة واستخدام أساليب التدريس والتقويم المتتوعة والملائمة لأنماط التفكير الواردة في نظرية الذكاءات المتعددة لجاردنر وهي (الذكاء اللفظي - اللغوي، والذكاء الفنطقي - الرياضي،

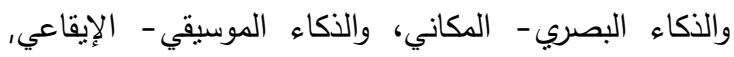

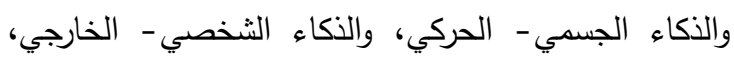
والذكاء الثخصي - الداخلي، والذكاء الطبيعي - البيئي). إستراتيجية القبعات الست: نظام يمكن الفرد من التفكير، من خلال تركيز تفكيره في نوع واحد من اتجاهات

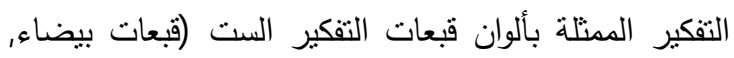
وقبعات حمراء، وقبعات سوداء، وقبعات صفراء، وقبعات خضراء، وقبعات زرقاء)، كما يمكن الفرد من نقل تفكيره وتوجيهه من نمط لآخر (Gross, 1998 ). أما في هذه الدراسة فهي تمنل إستراتيجية التدريس الدنضمنة مجموعة الخطوات والإجراءات المخططة والمرتبة من حيث تتفيذ الأشطة، واستخدام طرق التدريس والتقويم ووسائلها المتتوعة

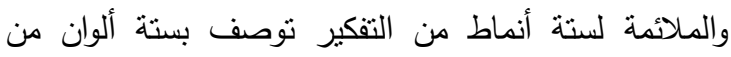
القبعات تزمز لطبيعة التفكير، من أجل نتظيم المعلومات وترتيبها وتقنينها حسب الموقف التعليمي وطبيعة المتعلمين، والأدوات التعليمية المتوفرة لأغراض هذه الدراسة. إستراتيجية حل المشكلات: عملية تفكيرية يقوم بها

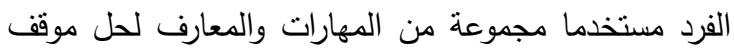

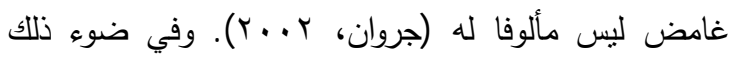
فهي مجموعة إجراءات التعلم والتعليم التي بستخدمها الطالب،

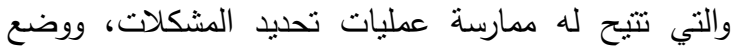
الفروض، وجمع المعلومات والبيانات من مصادرها المختلفة

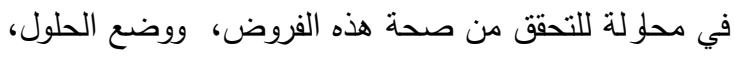
والوصول إلى التعميمات اللازمة. 


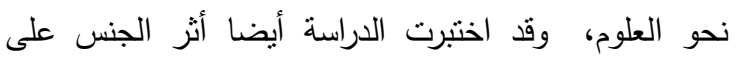

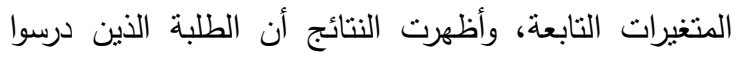
بأسلوب التدريس القائم على المشكلات لم يحرزوا تقدما في فهم الدفاهيم والاتجاهات نحو العلوم.

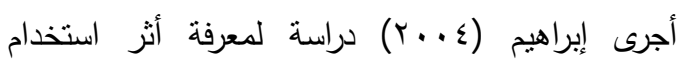

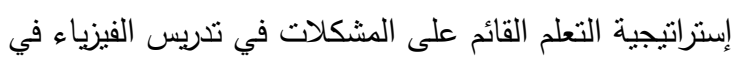
تتمية القدرة على التفكير الإبداعي والاتجاهات العلمية وفهم المفاهيم العلمية لاى طلاب الصف التاسع الأساسي في الإسي

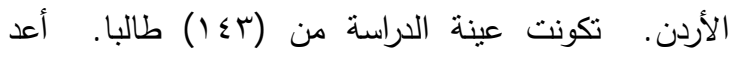
الباحث مادة علمية قدمت لطلاب المجموعة التجريبية بأسلوب التعلم القائم على المشكلات، في حين درست

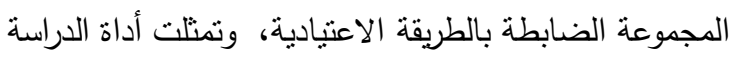

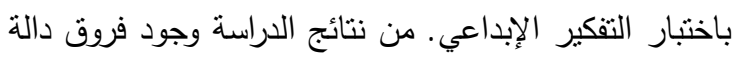

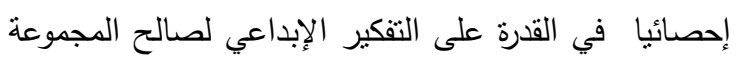
التي درست باستخدام التعلم القائم على المشكلات.

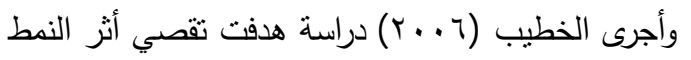

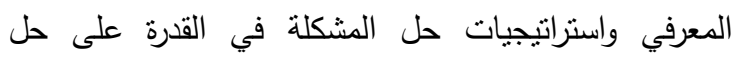

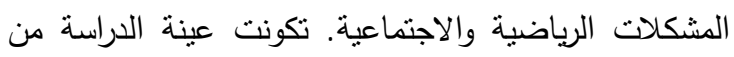

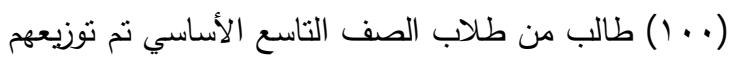

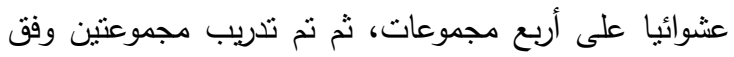

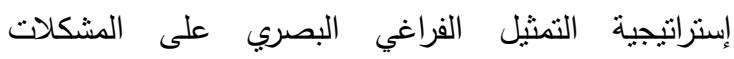
الرياضية، ومجموعنين وفق إستراتيجية التعلم التعلوني على التئي الشككلات الاجتماعية. تم استخدام الأدوات التالية: اختبار

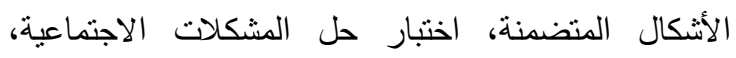

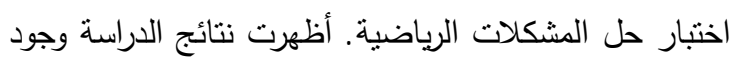

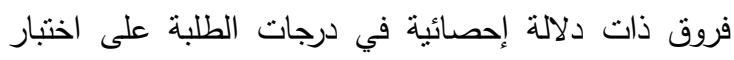

حل المشكلات الرياضية.

وهدفت دراسة مطالقة (Y..... إلى معرفة أثز التدريس

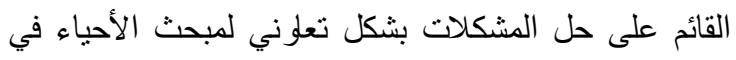

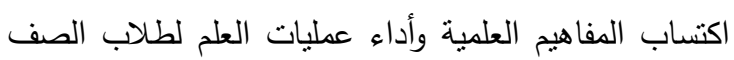

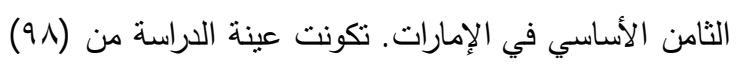

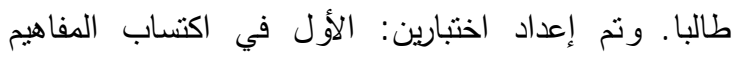

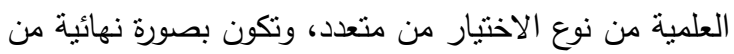

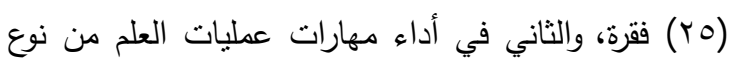
الاختيار من منعدد، وتكون بصورته النهائية من (· (Y) فقرة.

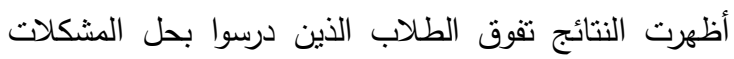

الصف الثامن عند تعلمهم بعض المفاهيم العلمية المتعلقة

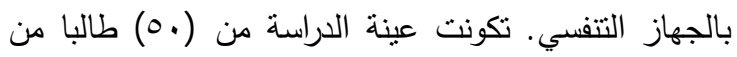
طلبة الصف الثامن في إحدى مدارس أنقرة. أظهرت الدراسة أهن وجود أثر للتدريس وفق نظرية الذكاءات المتعددة في الأداء التدريسي والتحصيل العلمي لاى الطلبة.

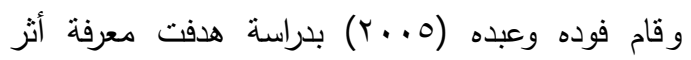
استخدام فنية دي بون وللقبعات الست، في تدريس العلوم

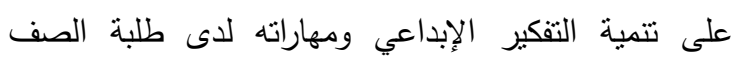
الخامس الابتدائي في إحدى مدارس جمهورية مصر العربية.

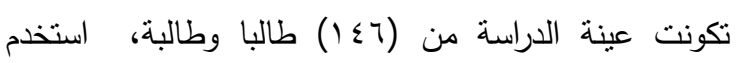
الباحثان مقياس نزعات التفكير الإبداعي، واختبار مهارات

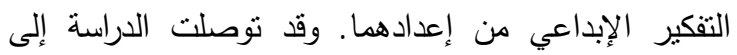

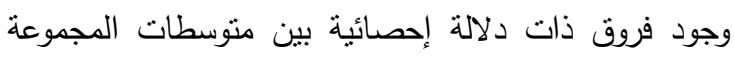

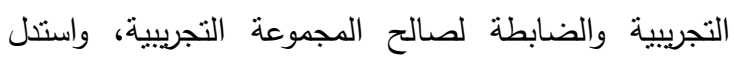

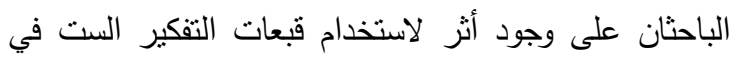
تتمية التفكير الإبداعي ومهاراته.

قام والتز (Walter, 1996) بدراسة استقصائية هدفت البحث عن أثر نموذج القبعات الست في التفكير، والجدل

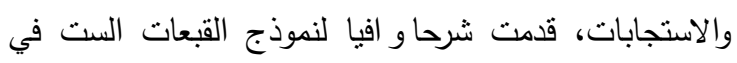
التفكير ونمط التفكير الخاص بكل قبعة من هذه القبعات. أجرى نوفاك (Novak, 2002) دراسة هدفت إلى معرفة أثز استخدام التدريس القائم على أسلوب حل المشكلات في تعلم الطلبة الموهوبين والمبدعين لمادة العلوم في الثاني الابتدائي في إحدى المدارس الخاصة في الولايات المتحدة

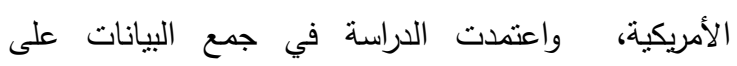
الملاحظة والمقابلة وتحليل نتائج الاختبار التحصيلي وتحليل

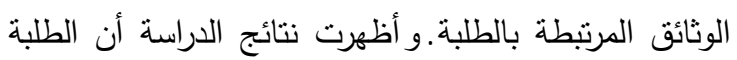
الذين درسوا بطريقة التنريس القائم على المشكلات لايهم قدرة

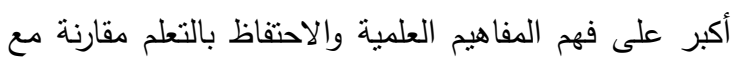
أو لئك الذين درسوا بالطريقة الاعنيادية.

(Williamson \& Perrow, وأجرى ويليامسون وبيرو (2003 دراسة هدفت معرفة أثز إستراتيجية التدريس القائم على المشكلات في تدريس "وحدة التقنيات الحيوية" في مادة الأحياء لطلاب الصفوف الأساسية في كل من فئل فهرمج للمفاهيم العلمية واتجاهاتهم نحو العلوم. تم استخدام اختبار لقياس مدى اكتساب المفاهيم واستبانة لقياس اتجاهات الطلبة 
أثر استراتيجيات: الذكاءات المتعددة وحل المشكلات والقبعات الست فِّ تنمية مهارات التفكير العلمي لدى طلبة الصف الثامن الأساسي يِّ الأردن فراس السليتي وخالد مفضي

العلوم، وبالتالي فإن هذه الدراسة أضافت بعدا جديدا لأثز هذه الإستراتيجيات في نتمية مهارات التفكير هذه

العلمي.

\section{الطريقة والإجراءات}

\section{منهجية الدر اسة:}

استخدم الباحثان المنهج شبه التجريبي الذي يتتاسب وطبيعة هذا البحث، وذلك من خلال نطبيق إستراتيجيات التدريس الثلاث على أفراد مجموعات الدراسة الثلاث.

\section{مجتمع الدراسة:}

تكون مجتمع الاراسة من جميع طلبة الثامن الأساسي في الأردن في الفصل الدراسي الأول للعام الدراسي

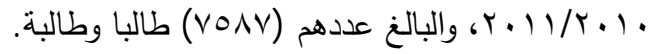

\section{أفر اد الدراسة:}

تكونت عينة الدراسة من (YIV) طالب وطالبة، تم

أخذهم من مجتمع الدراسة بالطريقة القصدية، منهم (1 • (1) طلاب و (9 1) طالبات، يتوزعون على ثلاث مجموعات، المجموعة الألى تم تدريسها وفق إستراتيجية الذكاءات المتعددة وتتكون من (TV) طالبا وطالبة، والمجموعة الثانية تم تدريسها وفق إستراتيجية حل المشكلات وتتكون من (VT) طالب وطالبة، والمجموعة الثالثة تم تدريسهاو فق إستراتيجية القبعات الست وتتكون من (VV) طالب وطالبة.و جدول (1) (1) يبين توزيع أفراد عينة الدراسة وفقا لمتغيري إستراتيجية

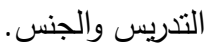

\section{جدول (1) جون (1)}

\begin{tabular}{|c|c|c|c|}
\hline \multicolumn{4}{|c|}{ توزيع أفراد العينة حسب متفيري الدارسة } \\
\hline المجموع & إناث & ذكور & الاستراتيجيات التدريسية \\
\hline & & & إستراتيجية الذكاءات \\
\hline & & & المتعددة \\
\hline vr & דץ & rV & إستراتيجية حل المشكلات \\
\hline VV & rᄉ & rq & إستراتيجية القبعات الست \\
\hline YIV & 1.9 & $1 \cdot 1$ & 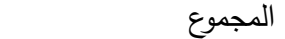 \\
\hline
\end{tabular}

\section{تكافؤ مـجمو عات الدر اسة:}

للتحقق من تكافؤ مجموعات الدراسة، تم حساب المتوسطات الحسابية والانحرافات المعيارية لدرجات أفراد
بشكل تعلوني على الطلاب الذين درسوا بالطريقة الاعتيادية في كل من اكتساب المفاهيم ومهارات عمليات العلم.

\section{تعقيب على الدراسات السابقة:}

بعد الاطلاع على مجموعة الاراسات السابقة ذات العلاقة بهذه الدراسة، يمكن استخلاص المؤشرات التالية منها: 1 ـ تعددت الدراسات التي تناولت استراتيجيات التدريس التي تعنى بالتفكير ، حيث تتاول بعضها استراتيجيات

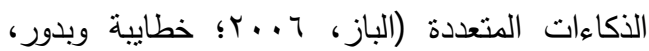

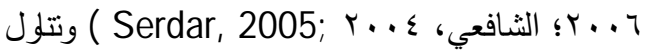
بعضها الآخر إستراتيجية القبعات الست (فوده وعبده،

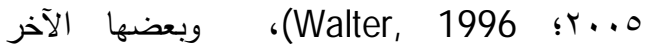
إستراتيجية حل المشكلات (الجراح، ج ؟ . ب؛ مطالقة، Novak, 2002; Williamson \& Perroe, ؛. . . V

.2003

r ـ الدراسات التي تتاولت أثز إستراتيجية القبعات الست في التدريس قليلة، سواء كان ذلك على المستوى العربي أو العالمي، واهتمت هذه الدراسات بالتحصيل (فوده وعبده، 0. . . ب؛ والتز ، 997 ( ).

r. تتاولت بعض الدراسات السابقة إستراتيجيات الذكاء المتعدد، حيث مسحت أنواع الذكاءات عند أفراد العينة

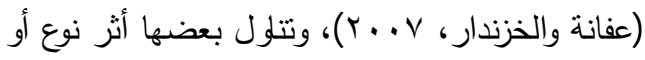
نوعين من أنواع الذكاءات على متغيرات محددة

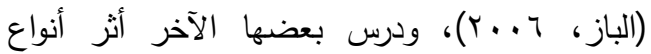
الذكاء مجتمعة على متغيرات معينة (الثافعي،

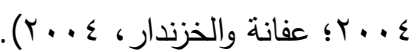

ع ـ أثارت بعض الاراسات إلى وجود فروق دالة إحصائيا لأثز استراتيجيات الذكاءات المتعددة، والقبعات الست، وحل المشكلات، في تحسين تعلم الطلبة (الباز،

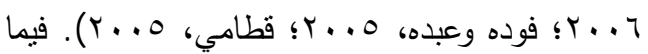

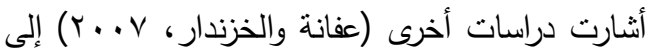
عدم وجود مثل هذه الفروق على بعض المتغيرات. ه. لم يتم العثور على دراسات اهتمت باستقصاء أثز الأكاءات المتعددة و القبعات الست و حل المشكلات معا في تتمية التفكير العلمي، عند تدريس محتوى 
النطبيق القبلي، ولتحديد مستويات الدلالة الإحصائية لتلك الفروق، ثم استخدام اختبار تحليل التباين الثنائي الذي أوضح عدم وجود جوهرية عند مستوى دلالة ه, · تعزى إلى أي من المتغيرات المستقلة (إستراتيجية التدربسن والجنس والتفاعل

$$
\text { بينهما) (1) }
$$

العينة على اختبار مهارات التفكير العلمي في التطبيق القبلي، حسب متغيري المجموعة والجنس، حيث كانت كما هي

موضحة في جدول (r).

يبين جدول (Y) أن هناك فروقا ظاهرية بين متوسطات درجات أفراد عينة الدراسة على مهارات التفكير العلمي في في فئ فئن

جدول (Y)

المتوسطات الحسابية والانحرافات المعيارية لارجات أفراد العينة على اختبار مهارات التفكير العلمي في التطبيق القبلي حسب التب

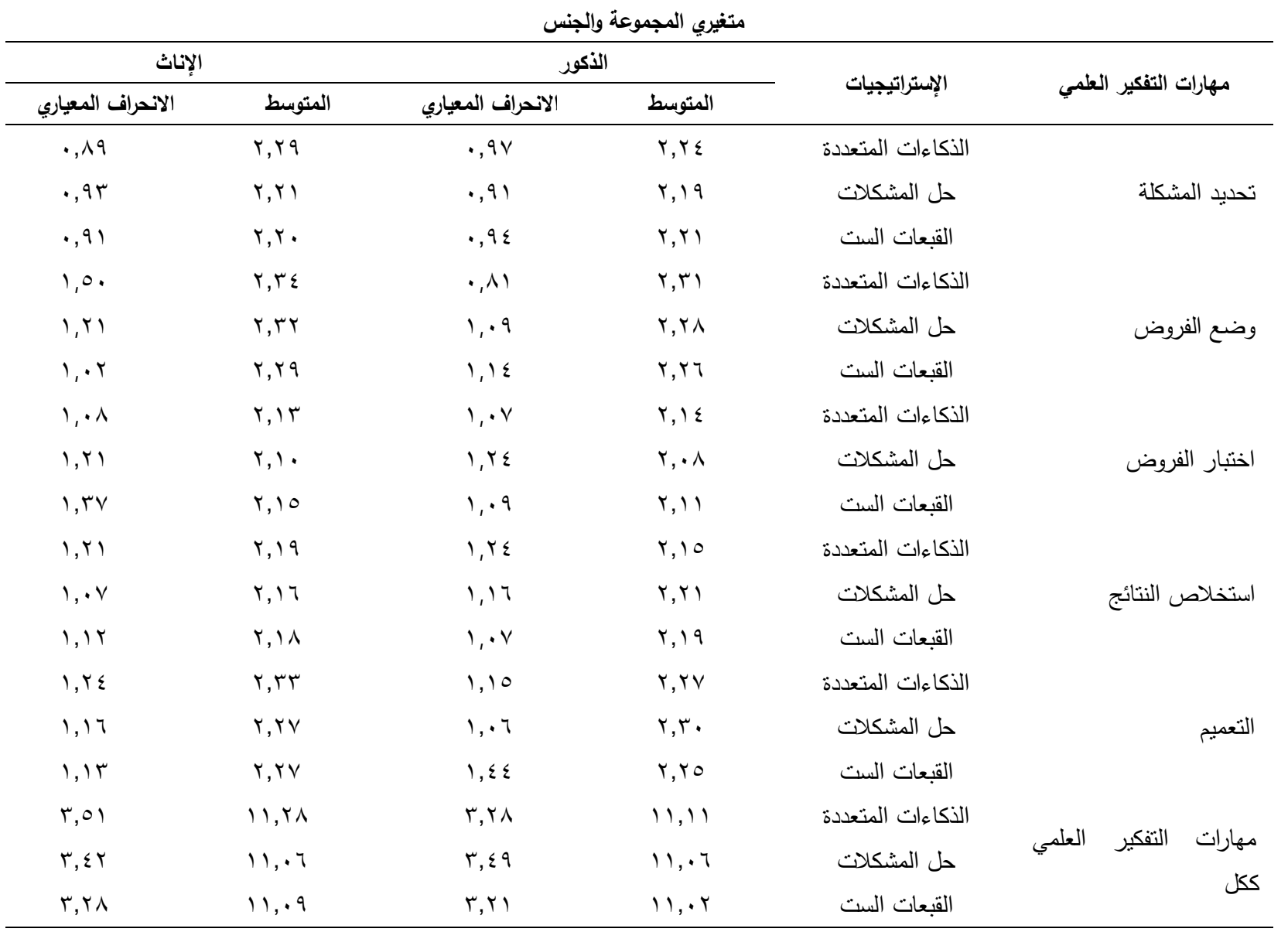

\section{أداة الدراسة:}

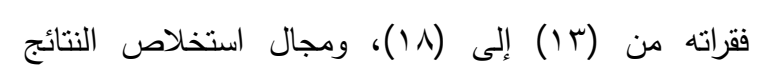

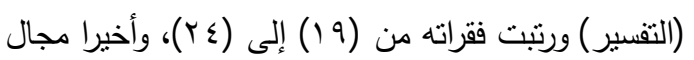
التعميم ورتبت فقراته من (ro) إلى (.r) . وكانت إجراءات بناء اختبار مهارات التفكير العلمي كما يلي: عين أ) تم الاطلاع على الأب التربوي والدراسات السابقة

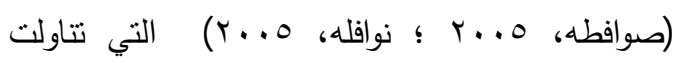
التفكير العلمي، بهدف التعرف على الأفكار والطرائق والمقاييس المستخدمة في قياس مستوى التفكير العلمي، وفي ضو ء ذلك اعتمدت خمسة مجالات لمهارات التفكير
بعد الرجوع إلى الأدب التربوي السابق والدراسات المتعلقة بالتقكير العلمي (القادري، ب . . r)، تم إعداد اختبار مهارات التفكير العلمي من نوع الاختيار من متعدد لقياس مهارات التفكير العلمي لاى الطلبة، وتكون هذا الاختبار من (•r) فقرة لكل منها (ع) بدائل، وقد توزعت هذه الفقرات بالتساوي ملهي على خمسة مجالات هي : مجال تحديد المشكلة ورتبت فقراته من (1) إلى (7)، ومجال وضع الفروض ورتبت فقراته من

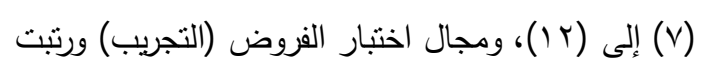


أثر استراتيجيات: الذكاءات المتعددة وحل المشكلات والقبعات الست فِّ تنمية مهارات التفكير العلمي لدى طلبة الصف الثامن الأساسي ِِّ الأردن فراس السليتي وخالد مفضي

المشكلة، ومهارة وضع الفروض، ومهارة اختبار الفروض، ومهارة استخلاص النتائج، ومهارة التعميم .

\section{ثبات اختبار مهارات التفكير العلمي:}

تم التأكد من ثبات الاختبار وذلك باستخدام ثبات التجانس الداخلي وفقا لتحليل إحصائيات الفقرة وذلك بتطبيق الاختبار على عينة استطلاعية من طلاب الصف الثامن، ومن نفس المجتمع مكونة من (rq) طالب وطالبة ولمرة

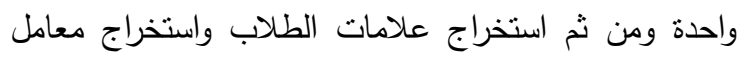
Kudr- الثبات باستخدام معامل كودر - ريتشاردسون (r)

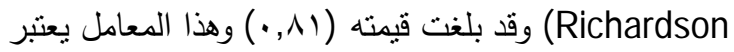
مقبولا لأغراض تطبيق الاختبار على عينة الدراسة. كما تم

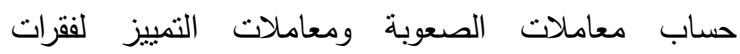
الاختبار، حيث كانت كما هي موضحة في جدول (T). يبين جدول (r) قيم معاملات الصعوبة ومعاملات التمييز

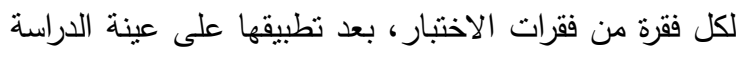
الاستطلاعية، حيث تراوحت معاملات الصعوبة بين (01,

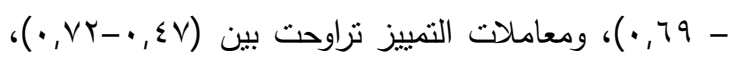

العلمي وهي: تحديد المشكلة، ووضع الفروض،و اختبار

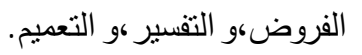
ب) وضعت فقرات الاختبار، وطبق على عينة استطلاعية

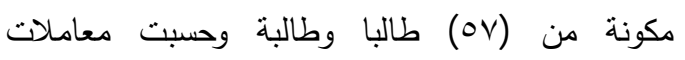

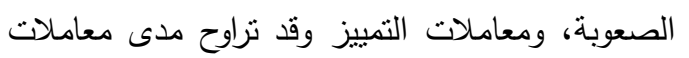

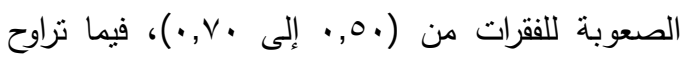

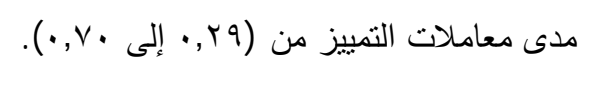
صدق اختبار مهارات التفكير العلمي: تم عرض اختبار مهارات التفكير العلمي المكون من فن من من

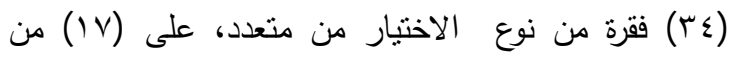

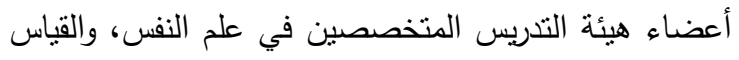

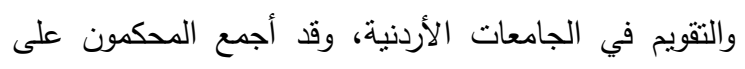

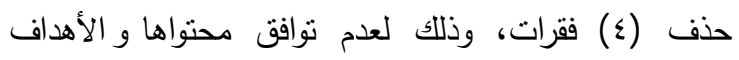

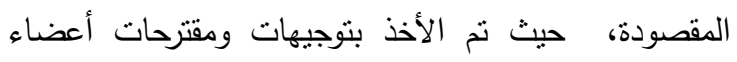
لجنة التحكيم، وتم تعديل الصياغة اللغوية لبعض الفقرات،

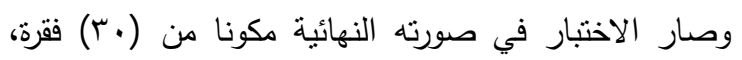
توزعت بالتساوي على خمس مهارات، وهي: مهارة تحديد

$$
\text { وهي قيم مقبولة لمثل هذه الدراسة. }
$$

جدول (r)

معاملات الصعوية ومعاملات التمييز لكل فقرة من فقرات الاختبار

\begin{tabular}{|c|c|c|c|c|c|}
\hline معامل التمييز & معامل الصعوية & رقم السؤال & معامل التمييز & معامل الصعوية & رقم السؤال \\
\hline$\cdot, T V$ & $\cdot, 09$ & r & $\cdot, \leqslant 9$ & $\cdot, 01$ & 1 \\
\hline$\cdot, 01$ & $\cdot, 7$ & $\varepsilon$ & זד, • &., $0 \mathrm{~V}$ & r \\
\hline$\cdot, 71$ & •, or & 7 & $\cdot, 00$ & $\cdot, 01$ & 0 \\
\hline$\cdot, 0 \leqslant$ & $\cdot, 00$ & $\wedge$ & $\cdot, \leqslant V$ & $\cdot, 09$ & V \\
\hline$\cdot, V Y$ & $\cdot, 70$ & 1. & זד, • & $\cdot, 0 \leq$ & 9 \\
\hline$\cdot, 09$ & זדו, & ir & $\cdot, 0$ & •, Or & 11 \\
\hline$\cdot, 00$ & $\cdot$, Or & $1 \leq$ & • & $\cdot, 70$ & 1 \\
\hline$\cdot, 0 \leqslant$ & $\cdot, 7 \varepsilon$ & 17 & $\cdot 77$ & $\cdot, 01$ & 10 \\
\hline$\cdot, 01$ & $\cdot, 79$ & 11 & $\cdot, \sum \vee$ & $\cdot, 7 \leq$ & iv \\
\hline אד, & $\cdot, 7$ & $r$. & ., or & $\cdot, 71$ & 19 \\
\hline$\cdot, 7 \leqslant$ & $\cdot, 70$ & rr & $\cdot, \leqslant \wedge$ & $\cdot, 01$ & r) \\
\hline., 01 &., 09 & $r \varepsilon$ & $\cdot, 7$ & $\cdot, 00$ & r \\
\hline$\cdot, 7 \wedge$ & $\cdot, T V$ & ry &., $0 \mathrm{~V}$ & $\cdot, 71$ & ro \\
\hline$\cdot, 0 \mathrm{~V}$ & • & $r \wedge$ & $\cdot, 71$ & $\cdot, 0 \leqslant$ & TV \\
\hline$\cdot, 09$ & $\cdot, 0 \leqslant$ & r. &., 00 &., 09 & rq \\
\hline., 01 & $\cdot, 09$ & & & & الاختبار ككل \\
\hline
\end{tabular}


وتمثل هذه المهارة قدرة الطالب على تقديم تعميم معين للظواهر المتشابهة ضمن الموقف المقصود .

\section{إجراءات الدراسة:}

تم تطبيق الدراسة حسب الإجراءات الآتية:

ا . تم تحديد مجتمع الدراسة والذي شمل جميع طلبة الصف الثامن الأساسي في مديرية تربية اربد الأولى

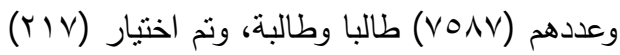
طالبا وطالبة منهم بالطريقة العثوائية العنقودية، وتم توزبع شعبهم الست إلى مجموعتين تجريبية وضابطة، ثم وزعت المجموعة التجريبية إلى س مجموعات يتم تدريس إحداها باستخدام استراتيجيات الذكاءات المتعددة، والأخرى باستخدام إستراتيجية

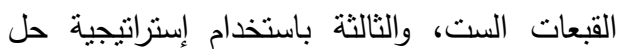
المشكلات .

r. عقدت جلسة أولية مع المعلمات والمعلمين المتعلونين كل على حده، وتم أخذ موافتهم للمساعدة في تتفيذ معالجات الدراسة وتطبيث

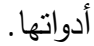

r. عقدت جلسة ثانية مع المعلمات والمعلمين المتعلونين تم فيها اختيار الوحدات الدراسية التي سيتم تتفيذها في هذه الدراسة بما يتوافق مع البرنامج التدربسي والخطط الفصلية لكل منهم، واتفق في هذه الجلسة على أن تشمل الوحدات التدريسية كلا من وحدتي الحرارة، والكثافة والمرونة. ع ـ أعد دليل المعلم ودليل الطالب واشنمل كل منهما على كافة المصادر والأدوات التي يحتاجها المعلم والطالب

$$
\text { في أثناء تتفيذ هذه الدراسة. }
$$

ه. حددت أساليب التقويم التكويني المناسبة للتدريس والتقويم وفقا لاستراتيجيات نظرية الذكاءات المتعددة، والقبعات الست، وحل المشكلات، ولمحتوى الوحدنين المقررتين والمعتمدتين في الدراسة، وتم تجهيز كافة الأدوات التعليمية اللازمة. 7. أعدت أداة الدراسة: اختبار مستوى التفكير العلمي، وتم التحقق من صدق وثبات الاختبار .

\section{تصحيح الاستجابة على فقرات الاختبار:}

تكون الاختبار بصورته النهائية من (·r) فقرة، لكل منها أربعة بدائل واحدة منها صحيحة، وقد أعطي الطالب العلامة

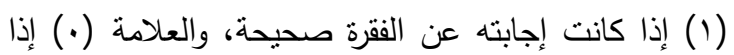
كانت إجابته خاطئة، وبالتالي فقد بلغت العلامة القصوى لهذا

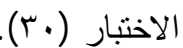

\section{و صف الاختبار:}

يضم اختبار التفكير العلمي في صورته النهائية، والذي تم تطبيقه في هذه الدراسة (·r) فقرة في خمسة مجالات

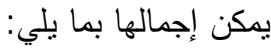

أولا: تحديد المشكلة: يتكون من الفقرات (ا إلى 7 ) وتمنل كل فقرة موقفا يتضمن مشكلة، وعلى الطالب القيام بتحديد هذه المشكلة تحديدا مناسبا من خلال البدائل الأربعة الموجودة ضمن هذه الفقرة، وتمثل هذه المهارة قدرة الطالب على تحديد السؤال الذي يصف المشكلة الرئيسية التي يطرحها الموقف الوارد في الفقرة.

ثانيا: وضع الفروض: وينكون من الفقرات (V) r) وتمنل كل فقرة موقفا يتضمن مشكلة، وعلى الطالب القيام باختيار الفرض المناسب من خله البدائل الأربعة

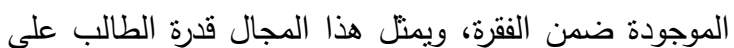
اختيار أنسب الفروض للمشكلة المطروحة.

ثالثا: اختبار الفروض (التجريب): ويتكون من الفقرات (rا إلى 11) وتتضدن كل فقرة مشكلة، وعلى احلى الطالب اختيار انسب الطرق لاختبار صحة الفرض، وتمثل هذه المهارة قدرة الطالب على اختيار أفضل الطرق لاختبار صحة الفرض الذي بطرحه الموقف الوارد في الفقرة. رابعا: استخلاص النتائج (التفسير): ويحتوي هذا المجال على الفقرات (9 إلى \&Y) و وتتضمن كل فقرة مشكلة، وعلى الطالب اختيار النتيجة المناسبة من بين البدائل الأربعة المطروحة، وتمنل هذه المهارة قدرة الطالب على استخلاص هل

النتيجة المناسبة وتفسيرها كحل للمشكلة المطروحة ضمن الموقف المقصود .

خامسا: التعميه: ويحتوي هذا المجال على الفقرات

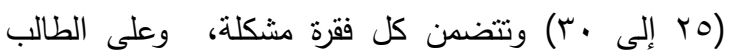
اختيار التعميم المناسب للحكم على مواقف أخرى مشابهة، 
أثر استراتيجيات: الذكاءات المتعددة وحل المشكلات والقبعات الست فِّ تنمية مهارات التفكير العلمي لدى طلبة الصف الثامن الأساسي يِّ الأردن فراس السليتي وخالد مفضي

ع ا . عقدت الجلسة الأخيرة مع المعلمات والمعلمين

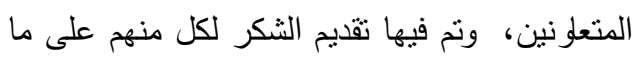
أبدوه من تعلون في أثناء تتفيذ الدراسة.

\section{النتائج}

حلولت هذه الدراسة الإجابة عن سؤال الدراسة الرئيس: ما أثز إستراتيجيات الأكاءات المتعددة وحل المشكلات والقبعات الست في تتمية مهارات التفكير العلمي لاى طلبة الصف الثامن الأساسي في الأردن؟ وقد انبثق عن هذا السؤال، الأسئلة الفرعية التالية؟ النئ

1. هل توجد فروق ذات دلالة إحصائية بين متوسطات درجات الطلبة في مهارات التفكير العلمي تعزى إلى

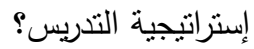
r . هل توجد فروق ذات دلالة إحصائية بين متوسطات درجات الطلبة في مهارات التفكير العلمي تعزى إلى الجنس؟ r. هل توجد فروق ذات دلالة إحصائية بين متوسطات

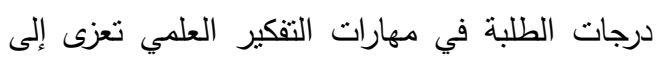
التفاعل بين إستراتيجية التدريس والجنس؟ للإجابة عن أسئلة الدراسة، تم حساب المتوسطات الحسابية والانحرافات المعيارية لدرجات أفراد العينة على اختبار مهارات التفكير العلمي، حسب منغيري إستراتيجية التدريس والجنس، حيث كانت كما هي موضحة في جدول

يبين جدول (ع ) أن هناك فروقا ظاهرية بين متوسطات درجات أفراد عينة الدراسة على مهارات التفكير العلمي، ولتحديد مستويات الدلالة الإحصائية لنلك الفروق، ثم استخدام اختبار تحليل التباين الثنائي، كما هو موضح في جدول (0). يبين جدول (0) وجود فروق ذات دلالة إحصائية عند

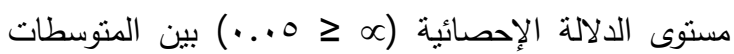
الحسابية لدرجات أفراد عينة الدراسة تعزى لمتغير إستراتيجية التدريس، عند جميع مهارات التفكير العلمي، ولتحديد مصادر تلك الفروق تم استخدام اختبار شافيه (Scheffe) كما هو موضح في جدول رقم (T) .
V. عقدت جلسات ثالثة ورابعة مع المعلمات والمعلمين المتعلونين تم فيها تزويدهم بدليل المعلم ودليل الطالب والخطط التدريسية والأدوات والمصادر التي تلزمهم لتتفيذ الدروس، وطلب منهم الإطلاع عليها، و ابداء الملاحظات التي يرونها مناسبة، كما طلب إليهم توزيع دليل الطالب على الطلبة والاحتفاظ به، وطلب إليهم تزويد الباحثين بملاحظاتهم حول المواد التعليمية المقدمة إليهم.

1. تم تدريب كل معلم ومعلمة من معلمي ومعلمات المجموعات التجربيية بجلستنين، تم فيهما تدريبهم على ملى آلية تتفيذ الإجراءات المطلوبة منهج، ونفذ الباحثان أمام كل منهم درسا في مبحث العلوم وفقا للإستراتيجية المطلوب من المعلم أو المعلمة تتفيذها، وتمت دئ مناقتنهم حول الحصص التدريسية التي نفذت أمامهم. 9 ـ تم الالتقاء مع المعلمين المتعلونين في مدارسهم للتأكد من الاستعداد لتتفيذ الدراسة، وتم تحديد موعد بدء تطبيق الدراسة وهو (1/ / / • 1 • rم) . • . . طبق اختبار مستوى التفكير العلمي القبلي في

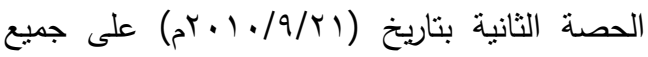
أفراد العينة التجريبية والضابطة، وصححت استجابات الطلبة على الاختبار، ورصدت النتائج.

11 . . تم البدء بتنفيذ الدروس من قبل جميع المعلمات والمعلمين المتعلونين في الأسبوع الأخير من شهر

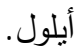

ץ ـ استغرق تتفيذ الدروس لكافة المجموعات التجريبية

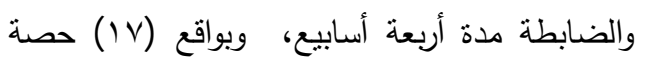

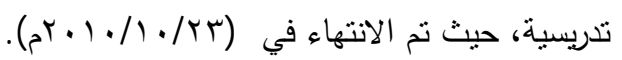
rا..طبق اختبار مستوى التفكير العلمي البعدي في

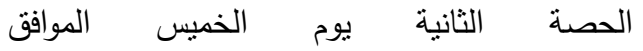

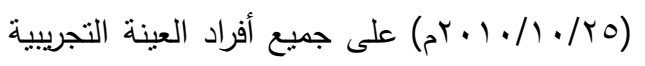
والضابطة، وصححت استجابات الطلبة على الاختبار، ورصدت النتائج. 
أفراد عينة الدراسة عند جميع مجالات الدراسة تعزى إلى متغير الجنس، حيث كانت الفروق التهاتية

$$
\text { لصالح الإناث. }
$$

r. عدم وجود فروق ذات دلالة إحصائية عند مستوى (.. بين المتوسطات الحسابية لدرجات

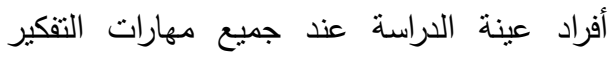
العلمي تعزى إلى التفاعل بين متغير إستراتيجية

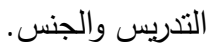

1. يبين جدول (T) أن هنآك فروقا ذات دلالة

إحصائية بين متوسط درجات الطلبة الذين درسوا

بإستراتيجية (القبعات الست) من جهة، ومتوسط درجات الطلبة الذين درسوا بإستراتيجيتي (الذكاءات المتعددة، وحل المشكلات) من جهة ثنانية، تعزى لإنى

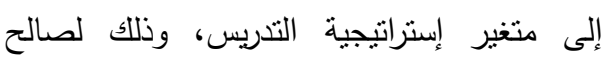
درجات الطلبة الذين درسوا بإستراتيجية (القبعات

r. وجود فروق ذات دلالة إحصائية عند مستوى (. بين المتوسطات الحسابية لدرجات

جدول (؛)

المتوسطات الحسابية والانلفوات المعيارية لدرجات أفراد العينة على اختبار مهارات التفكير العلمي حسب متفيري إستراتيجية التدريس و الجنس

\begin{tabular}{|c|c|c|c|c|c|}
\hline \multicolumn{3}{|c|}{ الإناث } & \multirow{2}{*}{ المتوسط الحسابي } & \multirow{2}{*}{ الاستراتيجيات } & \multirow{2}{*}{ مهارات التفكير العلمي } \\
\hline الانحراف المعياري & المتوسط الحسابي & الانحراف المعياري & & & \\
\hline$\cdot, 9$ & $\varepsilon, \wedge 9$ & I, rV & $\varepsilon,+7$ & الذكاءات المتعددة & \multirow{3}{*}{ تحديد المشكلة } \\
\hline$\cdot, \wedge 9$ & $\varepsilon, \wedge 1$ & 1, זה & r,ی & حل المشكلات & \\
\hline$\cdot, 0$ & $0, \Sigma Y$ & $\cdot, 0$ & $0, \Sigma \varepsilon$ & القبعات الست & \\
\hline$\cdot$, , & $\varepsilon, 9 \vee$ & חז, 1 & $\varepsilon, .9$ & الذكاءات المتعددة & \multirow{3}{*}{ وضع الفروض } \\
\hline$\cdot, \wedge \vee$ & $\varepsilon, \vee_{0}$ & $1, \leqslant 7$ & ґ,人т & حل المشكلات & \\
\hline$\cdot, 01$ & $0, \Sigma \vee$ & $\cdot, \leqslant 9$ & $0, \pi 4$ & القبعات الست & \\
\hline$\cdot, \vee \vee q$ & $0, \cdot r$ & (1, (1, ) & r, & الذكاءات المتعددة & \multirow{3}{*}{ اختبار الفروض } \\
\hline$\cdot, \wedge)$ & $\varepsilon, \vee_{0}$ & 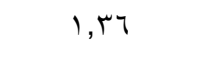 & $r, v \wedge$ & حل المشكلات & \\
\hline אד, & $0, r v$ & $\cdot, 0$ & $0, \Sigma 1$ & القبعات الست & \\
\hline$\cdot, v r$ & $0, \ldots$ & $1, \leq 0$ & $\varepsilon, \cdot r$ & الذكاءات المتعددة & \multirow{3}{*}{ استخلاص النتائج } \\
\hline$\cdot, 9 \leq$ & $\varepsilon, \vee_{0}$ & $1, \varepsilon r$ & $r, q)$ & حل المشكلات & \\
\hline$\cdot, 00$ & $0, \sum r$ & $\cdot, 0 \leqslant$ & $0, r 4$ & القبعات الست & \\
\hline$\cdot, 77$ & $0, \cdot 9$ & 1,ro & $\varepsilon, 17$ & الذكاءات المتعددة & \multirow{3}{*}{ التعميم } \\
\hline - & $\varepsilon, \vee \wedge$ & $1, \leqslant 7$ & 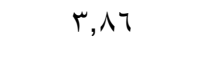 & حل المشكلات & \\
\hline$\cdot, 00$ & $0, \leqslant 0$ & אד, & $0, \mathrm{ru}^{-}$ & القبعات الست & \\
\hline $1, \varepsilon \varepsilon$ & $r \leqslant, 9 V$ & $r, 19$ & $r \cdot, \cdots$ & الذكاءات المتعددة & \multirow{3}{*}{ مهارات التفكير العلمي } \\
\hline $1, V 7$ & r & $r, Y \varepsilon$ & $19, Y V$ & حل المشكلات & \\
\hline 1, r & $r v, 1 r$ & $1, r Y$ & $r 7,9 r$ & القبعات الست & \\
\hline
\end{tabular}

جدول (o)

نتائج اختبار تحليل التباين الثنئي للفروق بين درجات أفراد عينة الدراسة على مهارات التفكير العلمي حسب متفيري إستراتيجية التريس والجنس

\begin{tabular}{|c|c|c|c|c|c|c|}
\hline الالالة الإحصائية & قيمة ف & متوسط المربعات & لدرجات الحرية & مجموع المريعات & المجالات & مصدر التباين \\
\hline${ }^{*}, \ldots$ & ห৭, \૫^ & rV.IrA & r & $O \leqslant, Y O V$ & تحديد المشكلة & \multirow{6}{*}{ إستراتيجية التدريس } \\
\hline$*, \ldots$ & $r \wedge, \cdots \varepsilon$ & $r 0,9 \cdot 1$ & r & $01, \lambda 1 \mathrm{~V}$ & وضع الفروض & \\
\hline$*, \ldots$ & rr,rqu & $r q, \varepsilon \cdot 1$ & r & $0 \wedge, \wedge \cdot 1$ & اختبار الفروض & \\
\hline$*, \ldots$ & $r \varepsilon, Y r \mid$ & rr,q7q & r & $\varepsilon v, q r v$ & استخلاص النتائج & \\
\hline${ }^{*}, \ldots$ & ro, 109 & $r r, 09 \varepsilon$ & r & $\varepsilon \vee, \mid \wedge \wedge$ & التعميم & \\
\hline$*, \ldots$ & $|r \wedge, r|$. & $7 \leq 7,1,1$ & r & Irqr,r.r & مهارات التفكير العله & \\
\hline
\end{tabular}


أثر استراتيحيات: الذكاءات المتعددة وحل المشكلات والقبعات الست ِِّ تنمية مهارات التفكير العلمي لدى طلبة الصف الثامن الأسـاسي ِِِ الأردن فراس السليتي وخالد مفضي

\begin{tabular}{|c|c|c|c|c|c|c|}
\hline الالالة الإحصائية & قيمة ف & متوسط المربعات & لدرجات الحرية & مجموع المربعات & المجالات & مصدر التباين \\
\hline${ }^{*}, \ldots$ & $19,00 \leqslant$ & $i v, \wedge \Lambda$. & $r$ & $\backslash \vee, \wedge \Lambda$. & تحديد المشكلة & \multirow{7}{*}{ الجنس الجن } \\
\hline${ }^{*}, \ldots$ & ri,vor & $r_{\cdot, r} r_{0}$ & r & $r_{\cdot}, r_{O}$ & وضع الفروض & \\
\hline${ }^{*} \cdot, \ldots$ & $r, 1 \leq r$ & $r q, i v$. & r & $r q, 1 v$. & اختبار الفروض & \\
\hline${ }^{*} \cdot, \ldots$ & $19,7 \vee r$ & $19,0 \leqslant 1$ & r & $19,0 \leq 1$ & استخلاص النتائج & \\
\hline${ }^{*} \cdot, \cdots$ & $r, r, \ldots$ & $r 1,190$ & 1 & $r 1,190$ & 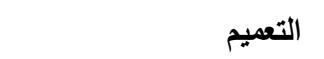 & \\
\hline${ }^{*} \cdot, \cdots$ & $11 \leq, 0 \leq \wedge$ & oro, \&NT & 1 & oro, \&ᄉT & مهارات التفكير العلمي ككل & \\
\hline ITH & $1, \cdot Y V$ & $\cdot, 949$ & r & l,AVV & تصديد المشكلة & \\
\hline . TVT & •,Aro & •, १५१ & r & 1, ort & وضع الفروض & \multirow{4}{*}{ تلتاعل إستراتيجية } \\
\hline$\cdots \leqslant r q^{\prime}$ & $\cdot, 7) \leqslant$ & $\cdot, 001$ & r & 1,110 & اختبار الفروض & \\
\hline$\because \vee \vee 99$ & • YVY & $\cdot$, YVT & r & $\cdot, 0 \leqslant 4$ & استخلاص النتائج & \\
\hline..$T \wedge V$ & $\cdot, \leqslant 9 \vee$ & •, $\{47$ & r & ·, qr & التعميم & \\
\hline \multirow[t]{13}{*}{..$r 09$} & $\cdot, \wedge \leqslant \uparrow$ & $r, 900$ & r & $v, q 1$. & مهارات التفكير العلمي ككل & \multirow{7}{*}{ الخطأ } \\
\hline & & $\cdot, q 49$ & rll & $19 V, 9 r r$ & تحديد المشكلة & \\
\hline & & •, १५१ & ru & 190,r|r & وضع الفروض & \\
\hline & & $\cdot, 9 \cdot 1$ & ru & $191, \varepsilon \wedge \lambda$ & اختبار الفروض & \\
\hline & & $\cdot, 9 \wedge 9$ & r) & $r \cdot \Lambda, V \backslash r$ & استخلاص النتائج & \\
\hline & & $\cdot, 94 \wedge$ & rI & $19 \vee, A V V$ & التعميم & \\
\hline & & $\varepsilon, 7 \vee 0$ & ril & 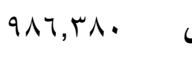 & مهارات التفكير العلمي ككل & \\
\hline & & & riT & Or.r & تحليد المشكلة & \multirow{6}{*}{ الكلي } \\
\hline & & & riT & Ort. & وضع الفروض & \\
\hline & & & rit & $0 . \wedge r$ & اختبار الفروض & \\
\hline & & & riT & Orr & استخلاص النتائج & \\
\hline & & & rit & orya & التعميم & \\
\hline & & & rit & MTIEST & مهارات التفكير العلمي ككل & \\
\hline
\end{tabular}

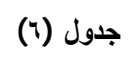

نتائج اختبار شافيه (Scheffe) للفروق بين درجات أفراد عينة الاراسة على مهارات التفكير العلمي حب متغيري إستراتيجية التُريس

\begin{tabular}{|c|c|c|c|c|c|}
\hline القبعات الست & حل المشكلات & الذكاءات اليتعددة & & إستراتيجية التدريس & \multirow{4}{*}{ تحديد المشكلة } \\
\hline $0, \varepsilon r$ & $\varepsilon, r r$ & $\varepsilon, \leqslant 9$ & المتوسط الحسابي & & \\
\hline${ }^{*} \cdot, 9 \leq$ & $\cdot, I V$ & & $\varepsilon, \leqslant 9$ & الذكاءات المتعددة & \\
\hline$* 1,11$ & & & $\varepsilon, r T$ & حل المشكلات & \\
\hline القبعات الست & حل المشكلات & الذكاءات المتعددة & & إستراتيجية التريس & \multirow{2}{*}{ المهارات } \\
\hline $0, r, r$ & $\varepsilon, r$. & $\varepsilon, 00$ & المتوسط الحسابي & & \\
\hline$* \cdot, \wedge \vee$ & r, ro & & $\{, 00$ & الذكاءات المتعددة & \multirow{2}{*}{ وضع الفروض } \\
\hline$* 1,1 \mathrm{r}$ & & & $\varepsilon, r$. & حل المشكلات & \\
\hline القبعات الست & حل المشكلات & الذكاءات المتعددة & & إستراتيجية التدريس & المهارات \\
\hline
\end{tabular}




\begin{tabular}{|c|c|c|c|c|c|}
\hline القبعات الست & حل المشكلات & الذكاءات المتعددة & & إستراتيجية التدريس & \multirow{3}{*}{ المهارات } \\
\hline $0, \varepsilon r$ & $\varepsilon, T_{T}$ & $\varepsilon, \varepsilon q$ & المتوسط الحسابي & & \\
\hline $0, r q$ & $\varepsilon, Y \uparrow$ & $\varepsilon, r V$ & المتوسط الحسابي & & \\
\hline$* 1, \cdot r$ & $\cdot, 11$ & & $\varepsilon, r v$ & الذكاءات المتعددة & \multirow{2}{*}{ اختبار الفروض } \\
\hline$* 1,1 \pi$ & & & $\varepsilon, Y_{T}$ & حل المشكلات & \\
\hline القبعات الست & حل المشكلات & الذكاءات المتعددة & & إستراتيجية التريس & \multirow{2}{*}{ المهارات } \\
\hline 0,49 & L, & $\varepsilon, 0 \leqslant$ & المتوسط الحسابي & & \\
\hline$*$, , ^० & $\cdot, r_{1}$ & & $\varepsilon, 0 \leqslant$ & الذكاءات المتعددة & \multirow{2}{*}{ استخلاص النتائج } \\
\hline$* 1, \cdot 7$ & & & ת & حل المشكلات & \\
\hline القبعات الست & حل المشكلات & الذكاءات المتعددة & & إستراتيجية التريس & \multirow{2}{*}{ المهارات } \\
\hline $0, \varepsilon$. & $\varepsilon, T$ & $\varepsilon, 7 \varepsilon$ & المتوسط الحسابي & & \\
\hline$\cdot, \vee \neg *$ & 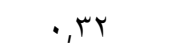 & & $\varepsilon, 7 \varepsilon$ & الذكاءات المتعددة & \multirow{2}{*}{ التعميم } \\
\hline$* 1, \cdot 1$ & & & $\varepsilon,{ }^{2}$ & حل المشكلات & \\
\hline القبعات الست & حل المشكلات & الذكاءات المتعددة & & إستراتيجية التدريس & \multirow{2}{*}{ المهارات } \\
\hline$r v, \cdot r$ & r1, or & $r r, T$. & المتوسط الحسابي & & \\
\hline$* \varepsilon, \varepsilon r$ & $1, \cdot 1$ & & rr, T. & الذكاءات المتعددة & مهارات التفكير \\
\hline $0,01 *$ & & & r1,Or & حل المشكلات & العلمي ككل \\
\hline
\end{tabular}

*ذات دلالة إحصائية عند مستوى الدلالة (> ه ., )

الست وحل المشكلات في مستوى التفكير العلمي مقارنة بالطريقة الاعتيادية، بما فسر في الأدب السابق من أن استراتجية الذكاء المتعدد تتضمن العديد من المواقف التي تحتاج إلى حل للمشكلات، مما يسهم في تتمية أساليب التفكير المختلفة لدى الطلبة على اختلاف قدراتهم وذكاءاتهم، وخاصة ما يتعلق منها بمهارات التقكير العلمي، كما أن هذه الإستراتيجية تتسم بتتوع الأنشطة المتضمنة فيها وبتعددها، فهي بذللك تتاسب جميع الذكاءات الموجودة لاى الطالب، وتمكنه من استثمار أكبر قدر ممكن من الذكاء الموجودة لديه، وفي نطوير العمليات العقلية المختلفة، منل : الملاحظة، وجمع البيانات، وضع الفروض، والتصنيف، والقياس

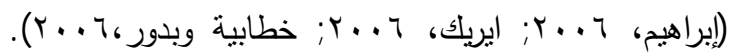
أما إستراتيجية القبعات الست فهي تتمحور حول الطالب، وتشركه في عملية التعلم، وفي البحث عن المعلومات (القبعة الزرقاء)، والتعبير عن المشاعر (القبعة الحمراء)، والتحذير من السلبيات والأخطاء ( القبعة السوداء)، والبحث عن الفوائد والحسنات (القبعة الصفراء) وتقديم البدائل والاقتر احات

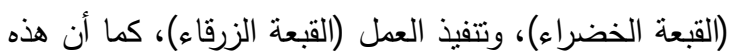

\section{المناقشة}

كان السؤال الأول في الاراسة: هل توجد فروق ذات دلالة إحصائية بين متوسطات درجات الطلبة في مهارات التفكير العلمي تعزى إلى إستراتيجية التدريس؟ تمثلت إجابة هذا السؤال في أن علامات مستوى التفكير العلمي لطلبة الصف الثامن اختلفت بدلالة إحصائية (0. ., ) وباختلاف إستراتيجية التدريس، ولصالح كل من استراتيجيتي الذكاء المتعدد والقبعات الست وحل المشكلات مقارنة بالطريقة الاعتيادية، ولإستراتيجية القبعات الست مقارنة باستراتيجيتي الذكاء المتعدد وحل المشكلات، ولكن لم تختلف علامات مستوى التفكير العلمي للطلبة باختلاف الجنس، أو للتفاعل بين الجنس و استراتيجية التدريس. وتتفق هذه مع ما توصلت إليها دراسات عدة مثل

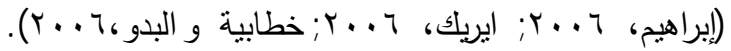
أما النتيجة الثانية فهي تتفق مع ما نوصلت إليها دراسة

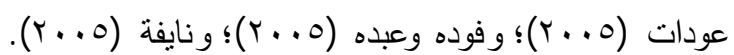
ويمكن تفسير تفوق أثز استراتيجيات الذكاء المتعدد والقبعات 
أثر استراتيجيات: الذكاءات المتعددة وحل المشكلات والقبعات الست فِّ تنمية مهارات التفكير العلهي لدى طلبة الصف الثامن الأساسي ِِّ الأردن فراس السليتي وخالد مفضي

التعليمية، بسبب جدية الطالبات وزيادة نشاطهن ـ وتتفق هذه

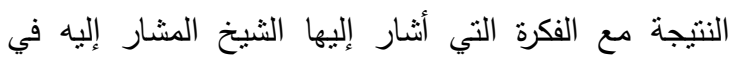
مصطفى (ع . . r) في أن معظم الإناث يستخدمن الجانب الأيسر من الدماغ أكثر من الذكور، وهو الجانب المسؤول

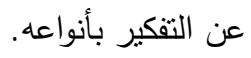

وفيما يتعلق بالتفاعل بين إستراتيجية التدريس والجنس

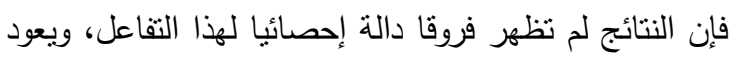
السبب في ذلك إلى أن فاعلية الاستراتيجيات المستخدمة على لطى أفراد العينة ذكور ا و اناثا كان متساويا.

\section{التوصيات}

في ضوء النتائج التي توصلت لها الدراسة ومناقشتها، فإن الدراسة توصي المعنيين من معلمين ومشرفين ومصمي لي

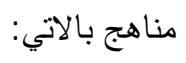

ا ـ التخطيط للتنريس بإستراتيجية الذكاء المتعدد والقبعات الست وحل المشكلات، والتدريب على تصميم مواقف تعليمية تعلمية بهذه الاستراتيجيات، وتضمين أدلة المعلمين للتدريس من خلالها . r إجراء المزيد من البحث في تحديد ملامح إجراءات التدريس بهذه الإستراتيجيات ومقارنة بين آثارها في التعليم والتعلم، وبين إستراتيجيات تعليمية تعلمية

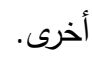

\section{المر اجع}

\section{المر اجع العربية: - المبية}

إبراهيم، بسام (ع . ؟).أثر استخدام التدريس القائم على

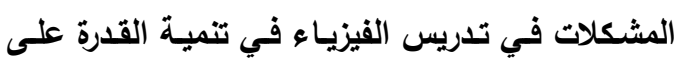
التفكير الإبـاعي والاتجاهـات العلميـة وفهـم المفـاهيم العلميـة لـى طـلاب الصـف التاسـع الأساسـي ـ رسـالة دكتوراه غير منشورة،الجامعة العربية، عمان،الأردن. إبراهيم، عبد الله (T . . ب ) . اثز برنامج في الذكاءات المتعددة

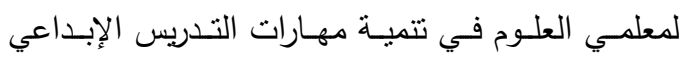
ومهارات حل المشكلات لدى تلاميذهم . مجلـة التربيـة

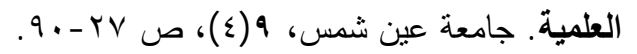

الإستراتيجية تهنم بالتفكير الجانبي (الموازي)، وتساعد الطالب في نركيز تفكيره باتجاه واحد؛ مما يساعده في إيجاد بدائل عديدة لحل المشكلة، واختيار انسب هذه البدائل. كما أن هذه الإسنراتيجية تسمح للطالب بتغيير نمط تقكيره; مما يجعل دوره مرنا وفعالا أكثز في حل المشكلات، وتمتاز هذه الاستراتيجيةبالتشويق وجذب الانتباه، و أعمال التفكير، وتزيد من دافعية الطلبة، وقدرتهم على التفاعل مع الموقف التعليمي بايجابية، مقارنة بطريقة التدريس العادية التي نزتكز على العرض والتلقين، والموقف السلبي من قبل المتعلمين

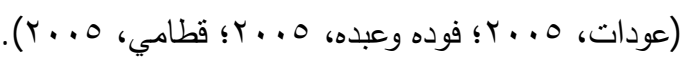
أما إستراتيجية حل المشكلات فقد أسههت في وصول الطلبة إلى حلول لمواقف جديدة، وذلك من خلال القواعد والقوانين والمبادىء التي تعلموها، وهي على مسنتى راق وعال مكنتهم من استخدامها في المواقف الجديدة المشابهة. كما ومكنت إستراتيجية حل المشكلات الطلبة من بذل جهد عقلي فريد حلولوا من خلاله إنجاز مهمات عقلية، والتخلص مله من العوائق الذي تعرضوا لها. أضف إلى ذلك أن الطلبة اكتسبوا المهارة أكثز من حصولهم على المعرفة، وذلك بعد أن طوروا إجراءات حل المشكلات، وكاملوا بين معرفتهم الإراكية ومهاراتهم الإجرائية، فتحسنت مهارات التعلم والتفكير ، ونمت الاستقلالية في التعلم، وكسبوا مهارات دراسية

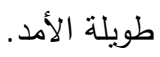

أما اختلاف علامات مستوى التفكير العلمي لطلبة الصف الثامن ولصالح طلبة إستراتيجية القبعات الست مقابل طلبة استراتيجيتي الذكاء المتعدد وحل المشكلات، فيمكن تفسيره في أن تبسيط التفكير وتوجيهه في إستراتيجية القبعات الست يساعد الطلبة أكثر في حل المشكلات، كما أن تركيز التفكير ومرونة التتقل بين أنماطه المختلفة يعطي الطالب حرية أكبر في الإبداع ووضع البدائل والحلول، ومن الممكن أن تكون إستراتيجية القبعات الست أكثر نشويقا من استراتيجيتي الذكاء المتعدد وحل المشكلات كونها تمنل نوعا

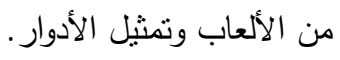

وبالنسبة إلى متغير الجنس فيمكن تفير اختلاف علامات مستوى التفكير العلمي لطلبة الصف الثامن، ولصالح الإناث في أن الطالبات يتفاعلن أكثر مع المواقف 
ديليسل، روبرت (1 . . ب) كيف تستخدم التعلم المستتد إلى

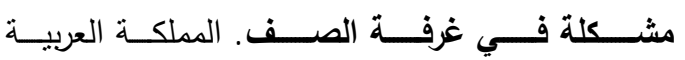
السعودية هددارس الظهران الأهلية.

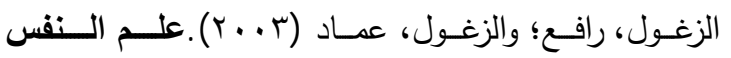
المعرفي. دار الثروق للنشر والتوزيع،عمان -الاردن. زيتون، عايش (1991) ) طبيعة العلم وينيته: تطبيقات في التربية العلمية ، ط2، عمان: دار عمار للنشر والتوزيع. زيتون، كمال (Y . . r) . تدريس العلوم للفهم : روئية بنائية. طا، القاهرة: علاء للكتب.

سـعادة، جـودت (919 (19) ) تـدريس الجغرافيـا بطريقـة حـل المشكلات مع نموذج تطبيقي لها على مشكلة الغذاء في

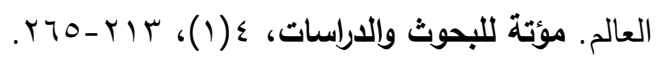
الشافعي، سنية (ع . . †) . توظيف الذكاء المتعدد باستخدام اسـتراتيجيات مقترحسة لتعليم العلـوم في تعلـيم المفـاهيم العلمية لتلاميذ المرحلة الإعدادية المهنية ، مجلة التربية العلمية،؛ (V)، كلية التزبية، جامعة عين شمس، القاهرة، . YTO- 199

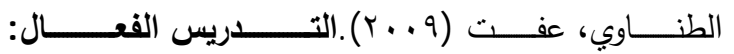

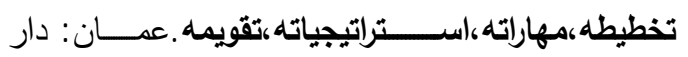

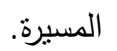
عبيدات، ذوقان وأبو السميد، سهيلة (v . . . r) . استراتيجيات التـدريس في القـرن الحـادي والعشـرين: دليـل المعــم والمشرف . عمان : دار الفكر . عفانة، اسماعيل و الخزندار ، نائلة (V. . . r). التدريس الصفي بالأكاءات المتعددة، عمان: دار المسيرة. عـودات، ميسـر (0 . . ب). اثخر اسـتخدام طرائسق العصـف الأهني والقبعات الست والمحاضرة المفعلة في التحصيل والتفكير التأملي للى طلبة الصف الثامن في مبحث التربيــة الوطنيــة فــي الأردن . أطروحسة دكتوراه غيـر منشورة،جامعة اليرموك،الأردن. فودة، ابراهيم وعبده، ياسر (0 . . ب). اثر استخدام فنية دي بون وللقبعات الست في تدريس العلوم على تتمية نزعات

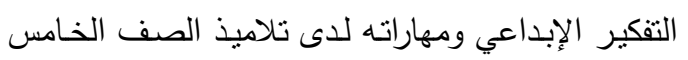

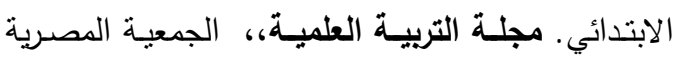

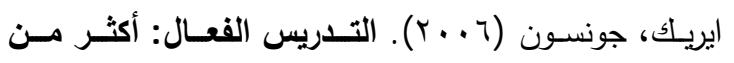

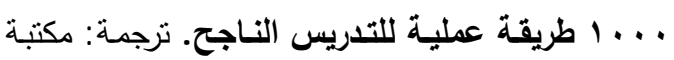

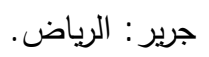

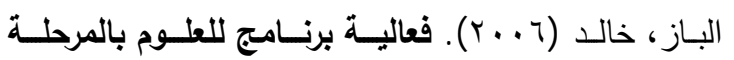
الابتدائية في ضوء نظرية الأكاءات المتعددة في تنمية التحصيل والذكاء الطبيعي وتعديل أنمـاط التعلم . دراسة مقدمة إلى المؤتمر العلمي الثامن للتزبية العلمية، كلية

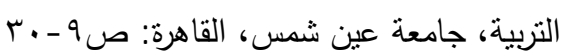

البغـدادي، محمـد رضـا (r . . r) . تــاريخ العلـوم وفلسـفة التربية العلمية. القاهرة: دار الفكر العربي. جروان، فتحي (Y . . Y). التفكير، مفاهيم وتطبيقات،

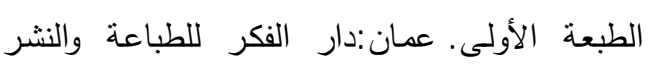
والتوزيع .

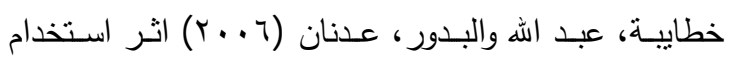
استراتيجيات الذكاءات المتعددة في تدريس العلوم في اكتسـاب طلبـة الصف السـابع الأساسي لعمليات العلم . رسالة الخليج العربي، و و، سו -77.

الخطيب، محمد إبراهيم أحمد (T . r) . أثز النمط المعرفي واستراتيجيات حل المشكلة في القدرة عل حل المشكلات الرياضسية والاجتماعيـة . أطروحة دكتوراه غير منشورة،

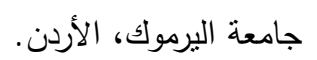
خليل، نـوال (؟ . r) . اثر استخدام استراتيجيات الذكاءات المتعددة في تتميـة التحصيل وعمليـات العلم الأساسية

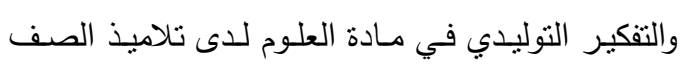

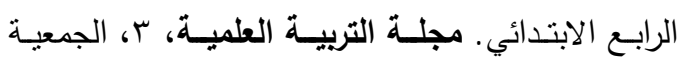

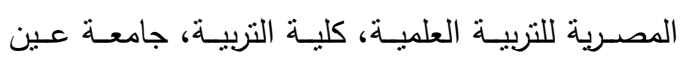
شمس، ص ص 01 - 99. الخوالدة، أحمد (ب . . ץ) . أثز استخدام أسلوب حل المشكلة في التحصيل والاحتفاظ بالتعلم في تدريس وحدة في النقد

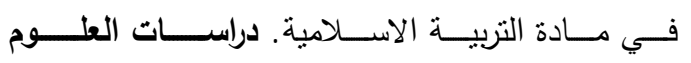

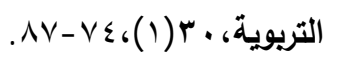

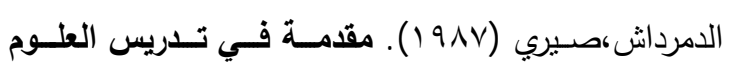
(ط ا ). القاهرة، دار المعارف. 
مطالقة، ماهر إبراهيم (V . . . . . أثز التدريس القائم على حـل المشـكلات بشـكل تعـأوني لمبحـث الأحبـاء فـي اكتسـاب المفـاهيم العلمية وأداء عمليـات العلم لطـلاب الصسـف الثـامن الأسـاسـي فـي دولـة الإمسارات العربيـة المتحـدة .رسـالة ماجستير غير منشـورةجامعة اليرمسوك،

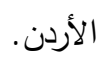

مهران، محمد أحمد وعفيفي، أحمد محمود (991 ) . فعالية بعض طرائق التدربس في تتمبـة القدرة على التفكيـر الابتكـاري لدى طلبـة كليـة التربيـة للمعلمين والمعلمـات

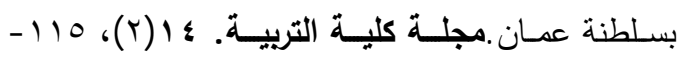

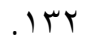

هـله، فتحي (7997) . قبـاس قدرات التفكير العلمي لدى

طلبـة الثانويـة العامة ونظلام المقررات في دولة الكويت.

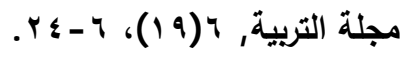

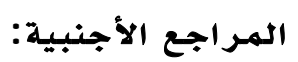

Anderson, J. (1995). Cognitive psychology and its implication (4th Eds).Freeman and company, New York.

Armstrong. L. (1994). M ultiple intelligence in the classroom. alexandria: association for aupervision and curriculum development. Michigan, USA.

Batchelor, S. (2000). Six hats thinking, a tool for participation in development, Christion outreach. NGO, Cambodia / UK.

Brown, J. (1995). O bserving dimensions of learning in classrooms and schools. Eric number: Ed 390166.

Cotton, K. (2001). Teaching Thinking skills. School Improvement Research Series (SIRS). Northwest Regional Educational Laboratory, Portland. Retrieved 10/3/2005 from: http:/ / www.nwrel.org/ scpd/ sirs/ 6/ cull.html

Davidson, N., \& Worsham, T. (1992). Enhancing thinking through cooperative learning. Teachers College Press, New York and London.

De Bono, E. (1992). Thinking course facts on file circle, 3rd edition. New York: Inc.

De Bono, E. (1999). Six thinking hats, MICA, Management Resources, Inc, chapter 1.

Gardner, H. (1983). Frames of mind, the theory of multiple intelligence. N ew York: Bascic Books.

$$
\begin{aligned}
& \text { للتربيـة العلميـة، كليـة التربيـة، جامعــة عـين شـمس، }
\end{aligned}
$$

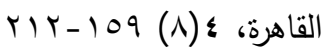

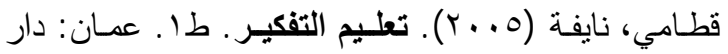

$$
\begin{aligned}
& \text { الفكر . } \\
& \text { كييف، جيمس وويلبرغ، هيربرت (س99 1) . التـريس مسن } \\
& \text { اجل تنمية التفكير, ترجمة: عبد العزيز البابطين، مكتب } \\
& \text { التربية العربي لدول الخليج: الرياض. }
\end{aligned}
$$

مصطفى، مصطفى (2004). فاعلية طريقة بنائية لتدريس

الكيمياء في تنميـة مهارات التفكير العلمي والتحصيل

للدى طلبـة المرحلـة الثانويـة في الأردن ـ رسـالة دكتوراه

غيـر منشـورة، جامعـة عمــان للاراسـات العليـا، عمــان:

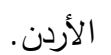

Goodenough. K. (2000). Exploring multiple intelligence's theory in the context of science approach. Dissertation Abstract International. 61/ 06:2164.

Gross, R. (1998). Peak Performance: The Six thinking hats, Armed Forces Comptroller, 43(3), 38.

Hurd, P.D. (1994). New minds for a new age: prologue to modernizing the science curriculum. Science Education, 70(1), 103-116.

Keith, T., Carolyn, P., Pauline, S. and Michelle, W.,(2004). Cross-age peer tutoring of science in the primary school: Influence on scientific language and thinking. Educational Psychology, $1,57-70$.

National Research Council, NRC.(1996). N ational Science Education Standers. Washington, D.C.: National Academy Press.

Novak, J. A. (2002). The implication and outcomes of using proble-based learning to teach middle school science.DA I-A 621 08,2718.

Mustafa, S. (2005). The Effect of Multiple Intelligences Theory (MIT)- based Instruction on Attitudes Towards the Course, Academic Success, and Permanence of Teaching on the Topic of "Respirator y Systems". Educational Sciences: Theory \& Practice. 7 (1).231-239 
Stanley, D, (1998). A usubel's Learning Theory: An A pproach to Teaching Higher order Thinking Skills. High School Journal, (1): 35-51.

Walter, J. (1996). Six thinking hats. Argumentativeness and response to thinking model, a paper presented at the annual conference of southern states communication association; March 1996, Memphis, Department of Communication Studies University of North Carolina at Chapel Hill.

Williamson, C., \& Perroe, C. (2003).The effect of problem-based learning on high school enrolled inbiology for the technology as measured by concept of self and attitude toward science.D A I-A 64\ 03,261.

Wilson, S. (2000). The role of musical intelligence in multiple intelligence's Florida elementary school. Dissertation Abstract International-A 60/ 03: 0684.

Yager, R. (2000). A vision for what science education should be like for the 25 years for a new millennia. School Science and M athematics, 100 (6), 327-341. 